Article

\title{
Evaluation of Subjective Feelings of Outdoor Thermal Comfort in Residential Areas: A Case Study of Wuhan
}

\author{
Kun Li* ${ }^{*}$, Tingting Xia and Wenya Li \\ School of Urban Design, Wuhan University, Wuhan 430072, China; tingtingxia@whu.edu.cn (T.X.); \\ liwenya@whu.edu.cn (W.L.) \\ * Correspondence: kunli@whu.edu.cn; Tel.: +86-186-2709-2645
}

Citation: Li, K.; Xia, T.; Li, W.

Evaluation of Subjective Feelings of Outdoor Thermal Comfort in Residential Areas: A Case Study of Wuhan. Buildings 2021, 11, 389. https://doi.org/10.3390/buildings 11090389

Academic Editor: Gianpiero Evola

Received: 3 August 2021

Accepted: 25 August 2021

Published: 1 September 2021

Publisher's Note: MDPI stays neutra with regard to jurisdictional claims in published maps and institutional affiliations.

Copyright: (C) 2021 by the authors Licensee MDPI, Basel, Switzerland. This article is an open access article distributed under the terms and conditions of the Creative Commons Attribution (CC BY) license (https:/ / creativecommons.org/licenses/by/ $4.0 /)$.

\begin{abstract}
Outdoor thermal comfort in urban residential areas is closely related to the daily lives of their residents. Nine residential communities in Wuhan, a typical city in central China, were selected as the research object. A questionnaire survey, meteorological parameter measurements, and data analyses were used to investigate the influences of factors such as the characteristics of the spatial environments and the types of outdoor activities undertaken by the residents on the levels of comfort. This investigation was expected to provide a reference for improving these levels. The results show that the level of satisfaction of those in areas with building heights of more than 15 stories reached $51 \%$. Wind speeds were higher in medium-density areas while comfort was the highest in residential areas with densities between $22 \%$ and $30 \%$. High-quality areas, which benefitted mainly from higher sensations of wind speed, had the highest levels of comfort but the strongest sensations of heat. A positive correlation exists between green areas and comfort. Where the green coverage rate exceeded $70.0 \%$, temperature satisfaction increased to $33.3-66.7 \%$. Areas with impervious paving are negatively correlated to temperature sensations. Areas of $400-625 \mathrm{~m}^{2}$ had levels of temperature satisfaction lower than $21.5 \%$
\end{abstract}

Keywords: urban residential area; thermal comfort voting (TCV); subjective evaluation; Wuhan

\section{Introduction}

In Chinese cities, green spaces are closely surrounded by buildings because of shortages in the land. The eco-performances of these spaces, especially in cities with hot summers and cold winters, where the outdoor thermal environments are relatively poor, are questionable [1-3]. The residential areas in these cities are the main living spaces and directly reflect the lifestyles of their residents [4]. However, the outdoor thermal comfort in such areas received little attention during their design phases, so problems with these living environments gradually emerged. Most of the conditions for outdoor thermal comfort cannot meet the needs of the outdoor activities of residents, who are eager for improvements in their current situations. Therefore, a study of the outdoor thermal comfort and the needs of those inhabiting residential areas is quite necessary [5-9]. Outdoor thermal comfort is far more difficult than indoor thermal comfort to study and evaluate [10] because of the complexities and instability of outdoor climates. Outdoor comfort is more closely related to people's daily lives, researchers should focus not only on specific climate and environmental indicators but also pay on the actual subjective feelings of residents, which are the starting point of our study.

The methods for studying outdoor thermal comfort include mathematical models, software simulations, questionnaire surveys, and field measurements. The current mathematical models for the assessment of comfort include several commonly used thermal comfort indexes, such as Predicted Mean Vote (PMV) [11], Standard Effective Temperature (SET) [12], Universal Thermal Climate Index (UTCI) [13], and Physiological Equivalent Temperature (PET) [14,15]. Zhaosong Fang et al. established mathematical models and 
compare the correlations for relationships among PET, UTCI, working temperatures, and relative humidity for the outdoor environment of Guangzhou University [16]. Ferdinando Salata et al. conducted a thermal sensation poll in the Mediterranean region and established a regression model with the respondents' PET values to determine the neutral PET values for winter and summer [17]. Negin Nazarian et al. used SET to predict outdoor thermal comfort and spatial variabilities in urban streets [18]. Mathematical models are quite suited to evaluating thermal comfort from the perspectives of human physiology and psychology but tend to ignore the complexities of the environments. Outdoor thermal comfort is also influenced by objective design elements such as site shapes, plant configurations, and underlying surface types.

Different environmental conditions and their effects on outdoor thermal comfort were simulated by software. Mohammad Taleghani et al. used ENVI-met to evaluate the outdoor thermal comfort of five different urban forms in the temperate climate of the Netherlands and found that the designs of courtyard spaces were conducive to comfort [19]. Hongyu Du et al. used Computational Fluid Dynamics (CFD) to simulate the thermal environments of water bodies, green spaces, and the central area in Shanghai, then put forward reasonable suggestions for urban planning and design [20]. Simulating the outdoor microclimates of the same site with different tree layouts in Phoenix, Arizona, United States, Qunshan Zhao et al. used ENVI-met to evaluate and compare the differences between the microclimates and their effects on human thermal comfort [21]. Although software simulations can effectively and intuitively evaluate the differences in thermal comfort due to different building layouts, plant configurations, and other environments, people are the main body of the environment and such simulations cannot incorporate their needs and feelings.

Studies were also conducted with the use of questionnaires and field measurements to assess outdoor thermal comfort. Min Xu et al. used a questionnaire survey to investigate the different levels of thermal comfort in different urban park landscapes in Xi'an, China, during winter, proving that landscape types and components had significant effects on the thermal environments and human thermal comfort [22]. Using microclimate measurements and self-filled questionnaire surveys, Fei Xue et al. studied methods for improving the microclimates of green open spaces in Hong Kong and Singapore, then found that their levels of spatial enclosures and green densities were significantly related to outdoor microclimatic conditions [23]. Using environmental measurements and simultaneous questionnaires, Sanaz Amindeldar et al. examined the relationship between climate data and subjective thermal sensations, then confirmed that individual variables (age and gender) and climatic variables (air temperature, solar radiation, and air velocity) had significant effects [24]. Lei Zhang et al. measured plant leaf density and corresponding meteorological data within a certain size of vertical green facades and found that they effectively reduced outdoor temperatures [25]. Jiaqi Niu et al. conducted meteorological measurements at six universities in $\mathrm{Xi}^{\prime}$ an and a questionnaire survey of 54 college students undertaking sports activities of different physical intensities, finding that the proportions of thermal discomfort increased by 33\%,50\%, and $83 \%$ for activities of light, medium, and strong intensity, respectively [26]. Shinichi Watanabe et al. conducted microclimate measurements and observed how pedestrians chose shaded areas in Nagoya, Japan, and concluded that "shadow design" in the city would be a key strategy to improving its safety, comfort, and attractiveness during hot weather [27].

Environmental measurements and questionnaire surveys are often used together. While measuring microclimate and microenvironmental data, they can also record the real feelings of the human body. Through the comparison and correlation of both methods, more comfortable environmental characteristics can be found. However, regardless of the method, studies on outdoor thermal comfort abound at the level of urban or campus environments in China but are lacking at the level of urban residential areas, especially those in cities with hot summers and cold winters. 
This study selected Wuhan, an area with hot summers and cold winters, as the research object and examined its residents' subjective feelings of outdoor thermal comfort in urban residential areas by means of a questionnaire survey, field measurements, and data analysis. The objectives were: (1) the current situations of outdoor thermal comfort during winter and summer; (2) a comparison of these situations for different planning characteristics during summer; (3) differences in the types of outdoor activities during both seasons to provide a basis for residential site planning; (4) the main underlying surface types that affect outdoor thermal comfort during summer.

\section{Study Site and Methods}

\subsection{Study Site}

Wuhan is located at $30.62^{\circ} \mathrm{N}$ and $114.13^{\circ} \mathrm{E}$ in the eastern part of the Jiang Han plain in the central part of China. The city has a subtropical humid monsoon climate with extremely high summer temperatures above $39^{\circ} \mathrm{C}$ and low winter temperatures below $-18{ }^{\circ} \mathrm{C}[28,29]$. In recent years, expanding urbanization has significantly changed the city's thermal environment. As the basic unit of a city, a residential area can directly reflect the lifestyles of its residents. Therefore, the objective of this study was to evaluate the outdoor thermal environments of nine areas and their characteristics, such as construction time, building layout, infrastructure configuration, and greening, and elucidate possible improvements. The specific distribution of these areas is shown in Figure 1.

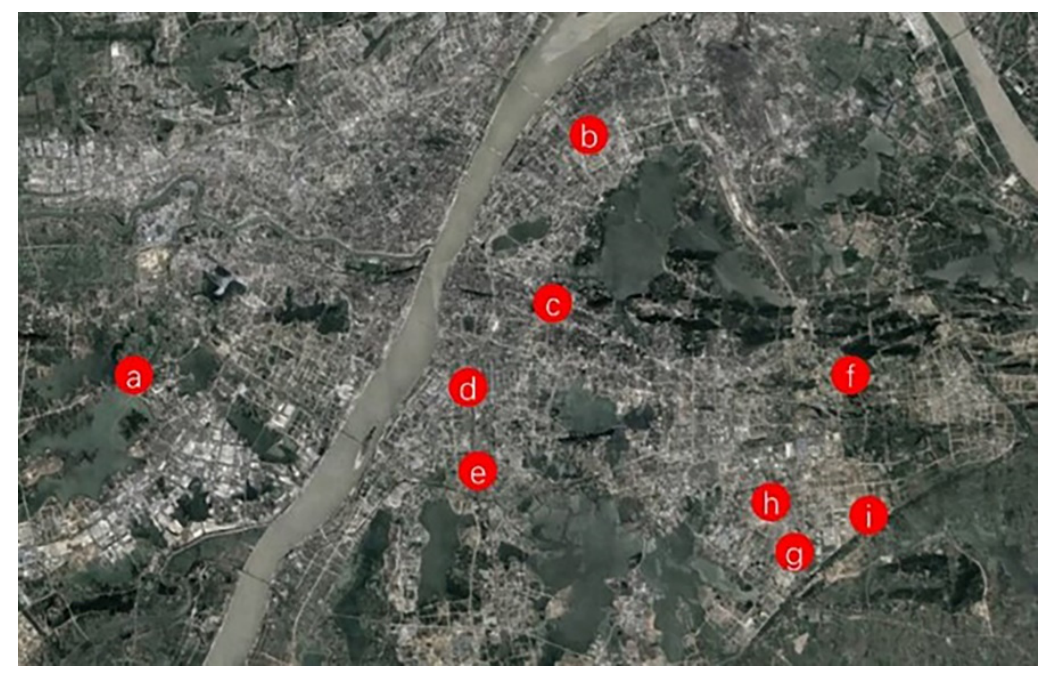

Figure 1. Locations of nine residential areas. (Graphics made with Google Maps as base). The letters on the figure represent the selected residential areas, which can be checked in Appendix A.

\subsection{Methods}

Field research by a questionnaire survey of each residential area and its basic current situation, outdoor environmental parameters was conducted. Sample points in each area were selected and a space of $25 \mathrm{~m} \times 25 \mathrm{~m}$ around each point was delimited as the research area. Appendix A contains descriptions of the situations and sample points.

\subsubsection{Environmental Parameters of the Study Site}

The environmental parameters of the residential areas are divided into two types: meteorological and planning. The meteorological parameters mainly reflect the climatic characteristics, which are the temperatures, humidity, and wind speeds, of the sample points. The planning parameters mainly reflect the designs elements, which are characteristics of the buildings (height and density), quality of the environment, and underlying surface types. Both types of parameters were measured, collected, and analysed for the environmental factors affecting outdoor thermal comfort. 


\section{(1) Measurements of Meteorological Parameters}

The meteorological parameters were measured while the questionnaire survey was being administered. To prevent interference, instruments measuring air temperature, relative humidity, and wind speed were set at heights of $1.1 \mathrm{~m}$ from the ground and horizontal distances of $1 \mathrm{~m}$ from the interviewees. The instruments are shown in Figure 2.

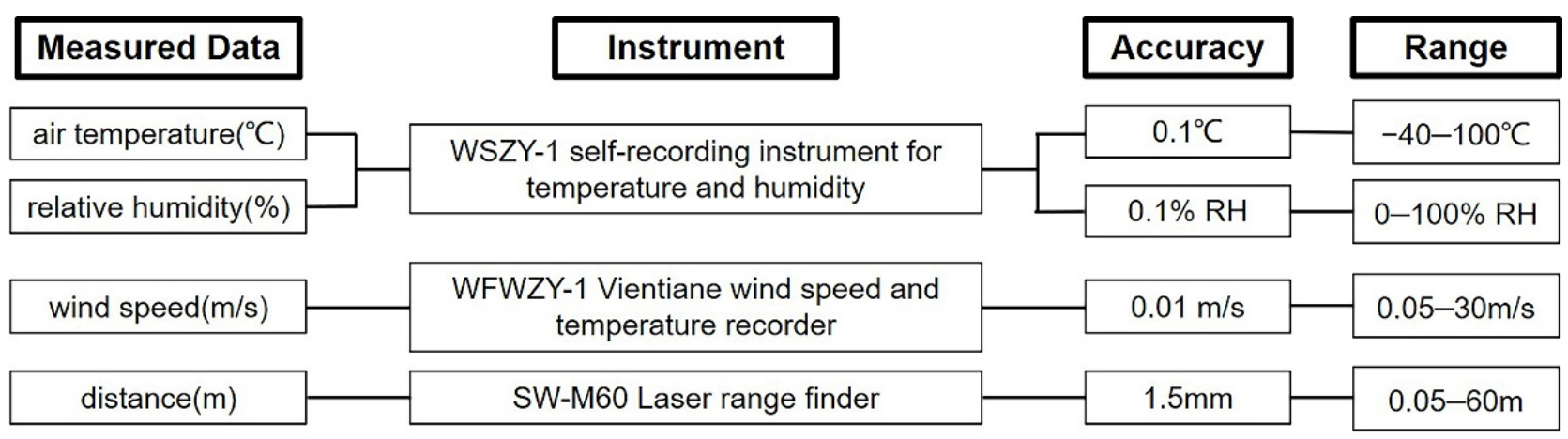

Figure 2. Instruments for measuring meteorological parameters.

(2) Classifications of Planning Parameters

The nine residential areas were classified according to building height, building density, and environmental quality.

i. Building height was further classified into three types according to the number of stories in the buildings, as shown in Table 1: (a) low-rise: less than 5 stories, (b) middle-high-rise: 6-15 stories, and (c) high-rise: more than 15 stories.

ii. Building density was also classified into three types according to the floor area ratio (FAR), as shown in Table 2: (a) low: $0<$ FAR $\leq 22 \%$, (b) medium: $22 \%<$ FAR $\leq 30 \%$, and (c) high: $30 \%<$ FAR $\leq 50 \%$ [30].

iii. Environmental quality was also classified into three types according to economic level [31], which was measured by the sales price per square meter as of October 2020 in Wuhan, as shown in Table 3: (a) low: less than 16,000 yuan $/ \mathrm{m}^{2}$, (b) medium: $16,000-22,000$ yuan $/ \mathrm{m}^{2}$, and (c) high: more than 22,000 yuan $/ \mathrm{m}^{2}$. Here, according to the exchange rate on 20 August 2021, 1 yuan equals 0.1583 U.S. dollars.

(3) Underlying Surface Measurements

Different types of outdoor underlying surfaces have different, direct effects on microclimates at the micro-scale and have consequent effects on the thermal comfort of the residents near those surfaces [32]. Drawing upon prior field investigations on the residential communities in Wuhan, this study measured three types of outdoor underlying surfaces-green areas, water bodies, and areas with impervious paving —within the scopes of the sample points.

Table 1. Classification of residential areas by building height.

\begin{tabular}{cccccc}
\hline & Low-Rise & \multicolumn{2}{c}{ Middle-High-Rise } & \multicolumn{2}{l}{ High-Density } \\
\hline Label & Name & Label & Name & Label & Name \\
\hline a & Oriental Hawaii Villa & $\mathrm{b}$ & Gang Hua Village & $\mathrm{c}$ & Zhang Jia Wan Community \\
$\mathrm{e}$ & Ban Qiao Community & $\mathrm{g}$ & Vanke City Garden & $\mathrm{d}$ & Central Garden Residential Area \\
$\mathrm{f}$ & Hong Jing Garden Villa & $\mathrm{i}$ & Residential Area & $\mathrm{h}$ & Vanke Jing Yuan Residential Area \\
\hline
\end{tabular}


Table 2. Classification of residential areas by building density.

\begin{tabular}{cccccc}
\hline & Low-Density & & Medium-Density & \multicolumn{2}{c}{ High-Density } \\
\hline Label & Name & Label & Name & Label & Name \\
\hline a & Oriental Hawaii Villa & $\mathrm{c}$ & Zhang Jia Wan Community & $\mathrm{b}$ & Gang Hua Village \\
$\mathrm{f}$ & Hong Jing Garden Villa & $\mathrm{g}$ & Vanke City Garden Residential & $\mathrm{d}$ & Central Garden \\
$\mathrm{i}$ & Fo Zu Ling Community & $\mathrm{h}$ & Vanke Jing Yuan Residential Area & e & Residential Area \\
Ban Qiao Community \\
\hline
\end{tabular}

Table 3. Classification of residential areas by environmental quality.

\begin{tabular}{cccccc}
\hline \multicolumn{2}{c}{ Low Environmental Quality } & \multicolumn{2}{c}{ Medium Environmental Quality } & \multicolumn{2}{c}{ High Environmental Quality } \\
\hline Label & Name & Label & Name & Label & Name \\
\hline $\mathrm{b}$ & Gang Hua Village & $\mathrm{a}$ & Oriental Hawaii Villa & $\mathrm{c}$ & Zhang Jia Wan Community \\
$\mathrm{e}$ & Ban Qiao Community & $\mathrm{d}$ & Central Garden & $\mathrm{g}$ & Vanke City Garden Residential \\
$\mathrm{i}$ & Fo Zu Ling Community & $\mathrm{f}$ & Residential Area & Area & Vong Jing Garden Villa \\
\hline
\end{tabular}

\subsubsection{Questionnaire Survey}

A questionnaire survey is a commonly used method to research outdoor thermal comfort and can accurately record people's corresponding subjective reactions to their environments $[33,34]$. Questionnaires were distributed to residents in the nine areas at locations within $25 \mathrm{~m} \times 25 \mathrm{~m}$ designated of the sample points. The summer survey was conducted twice a day with the distribution of questionnaires from 8:00 to 11:00 $\mathrm{h}$ and 14:00 to $19: 00 \mathrm{~h}$ from 16 July to 31 July 2018 , except for 25 July to 28 July, during which rain prevented the survey. The winter survey was conducted from 8:00 to 19:00 h. Every day from 10 December to 18 December 2018. The highest daily average temperature during the summer survey period was higher than $35^{\circ} \mathrm{C}$ and the lowest daily average temperature during the winter survey period was lower than $5^{\circ} \mathrm{C}$. Finally, 687 and 270 valid questionnaires were received in the summer and winter, respectively.

The questionnaire consisted of two main parts. The first part enquired about a resident's basic information, such as gender, age, length of residency, frequency of outdoor activities, and choice of outdoor venues. The second part enquired about the degree of the resident's satisfaction with their area's wind speed, temperature, and humidity. The questionnaire (Table 4) was referred to the ANSI/ASHRAE 55-2017 standard [35]. The temperature sensation voting (TSV) used a seven-level scale based on the previous studies [36]. The thermal comfort voting (TCV), the humidity sensation voting (HSV), and draft sensation voting (DSV) used five-level scales because the residents cannot distinguish these feelings and experiences too finely.

\subsubsection{Analytical Methods}

Data analysis software such as Microsoft Excel and SPSS [37] were used to collate and analyse the residents' basic information and their responses. Microsoft Excel was used to generate charts and compare the results under different conditions in winter and summer. Spearman correlation analysis was used for the measurements of the underlying surfaces and the residents' average thermal comfort [38]. By comparing the positive and negative correlation coefficients with the absolute value of the correlation coefficient at a significance level of 0.01 , we explored the main underlying surface design elements affecting outdoor thermal comfort. 
Table 4. Questionnaire used in survey.

\section{Thermal Environment Survey \\ Gender:}

Age:

(1) How long have you lived in the community?
$\square$ Less than one year
$\square$ One to three years
$\square$ More than three years

(2) How often do you visit the outdoor community spaces?
$\square$ Daily
$\square$ Several times a week
$\square$ Several times a month
$\square$ Usually do not visit

(3) Where do you like to go? Inside or outside the community?
$\square$ Inside the community
$\square$ Shopping malls around the community
$\square$ Gardens around the community

(4) What do you do outdoors?
$\square$ Running
$\square$ Chatting
$\square$ Walking the dog
$\square$ Dancing
$\square$ Swimming
$\square$ Fitness
$\square$ Playing chess
$\square$ Find solitude
$\square$ Playing with children

$\square$ Other choices

(5) Where do you prefer to exercise or rest?
$\square$ Flower bed
$\square$ Open square
$\square$ Water's edge
$\square$ Under a tree
$\square$ Indoor activity centre
$\square$ Lawn
$\square$ Raised platforms

(6) (TCV) Do you feel comfortable in the community?

$\square$ Very comfortable $\square$ Comfortable $\quad \square$ Neutral $\quad \square$ Uncomfortable $\square$ Very uncomfortable

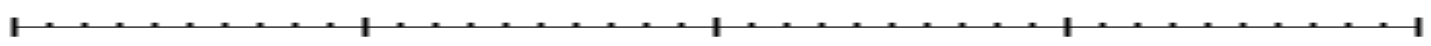
1
2
3
4

5

(7) (TSV) How do you feel about the temperature?

\begin{tabular}{|c|c|c|c|c|c|c|}
\hline$\square$ Cold & $\square$ Cool & $\square$ Slightly cool & $\square$ Neutral & $\square$ Slightly warm & $\square$ Warm & $\square$ Hot \\
\hline-3 & ? & 1 & 0 & & & +3 \\
\hline
\end{tabular}

(8) (HSV) How do you feel about the humidity?

$\square$ Very dry $\square$ Dry $\quad \square$ Neutral $\quad$ Damp $\quad \square$ Very damp

(9) (DSV) How do you feel about the wind speed?

$\square$ Still $\square$ Breezy $\square$ Windy $\quad \square$ Gusty $\quad \square$ Strong breeze

\section{Results}

We analysed the results to discover how the residential areas' building heights, building densities, and environmental quality affected the outdoor thermal comfort of the residents.

\subsection{Current Conditions of Residential Areas in Summer and Winter}

Using the data on TCV, which are shown in Figure 3, obtained by the survey, we made a comparative analysis of the outdoor thermal comfort values in winter and summer as expressed by the sum of the proportions of the residents who had voted, "very comfortable" and "comfortable". The proportions of the residents who voted "neutral" or "windy" represent the satisfaction values of the temperature, humidity, and wind sensations, which 
are explanatory indicators for thermal comfort. The satisfaction value is divided by the hierarchical system of the traditional scoring system and the ranges of the values are divided into three grades [39] to rate the thermal comfort of the outdoor environment: $0-33.3 \%$ (low), 33.3-66.7\% (moderate), and 66.7-100.0\% (high).

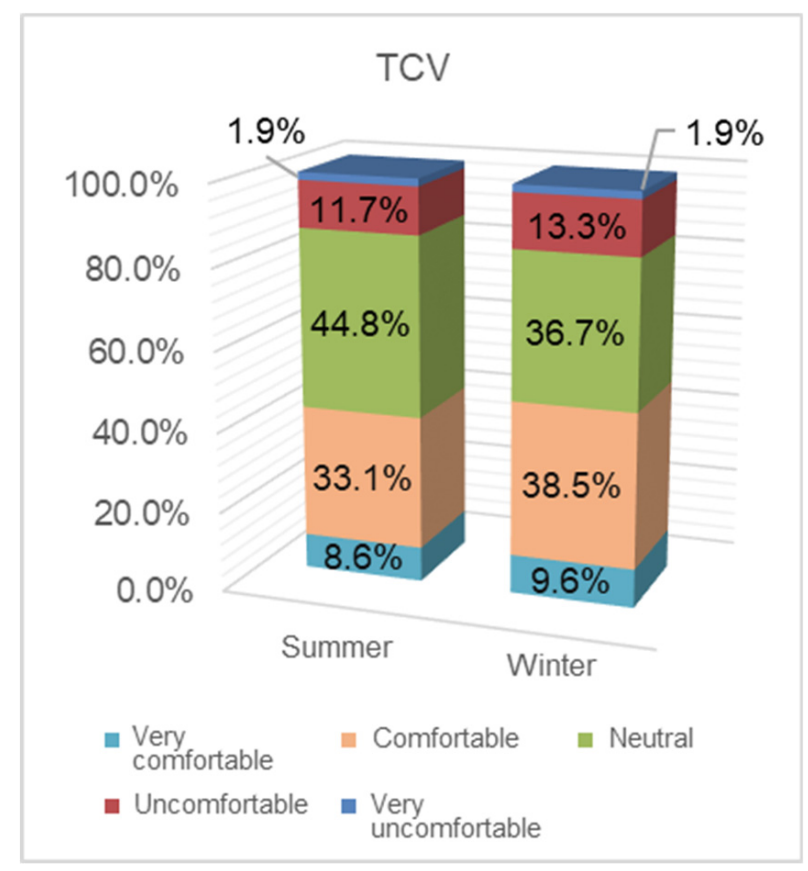

(a)

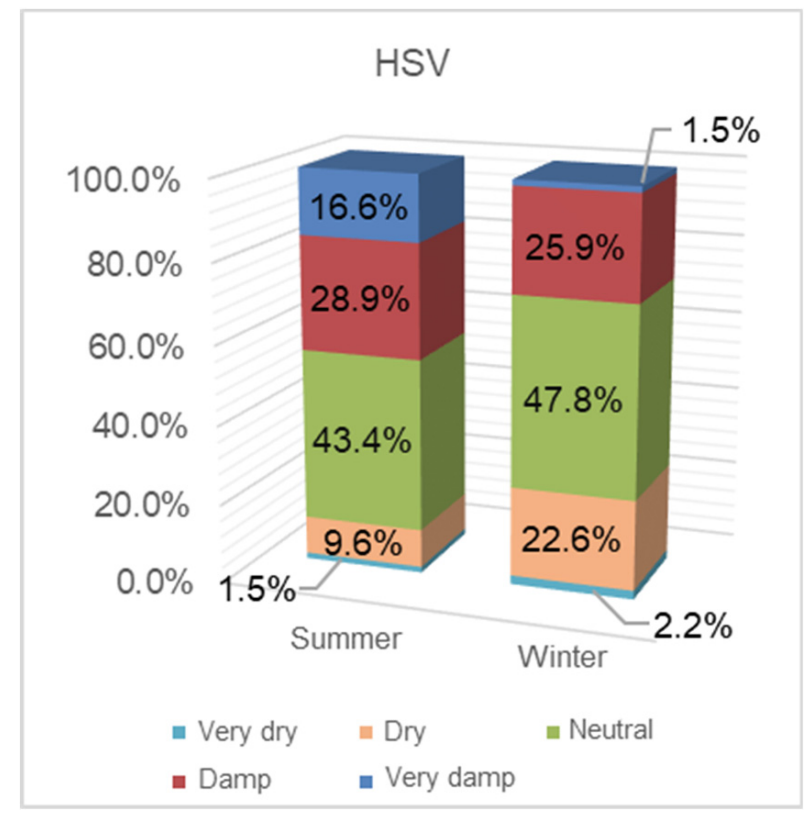

(c)

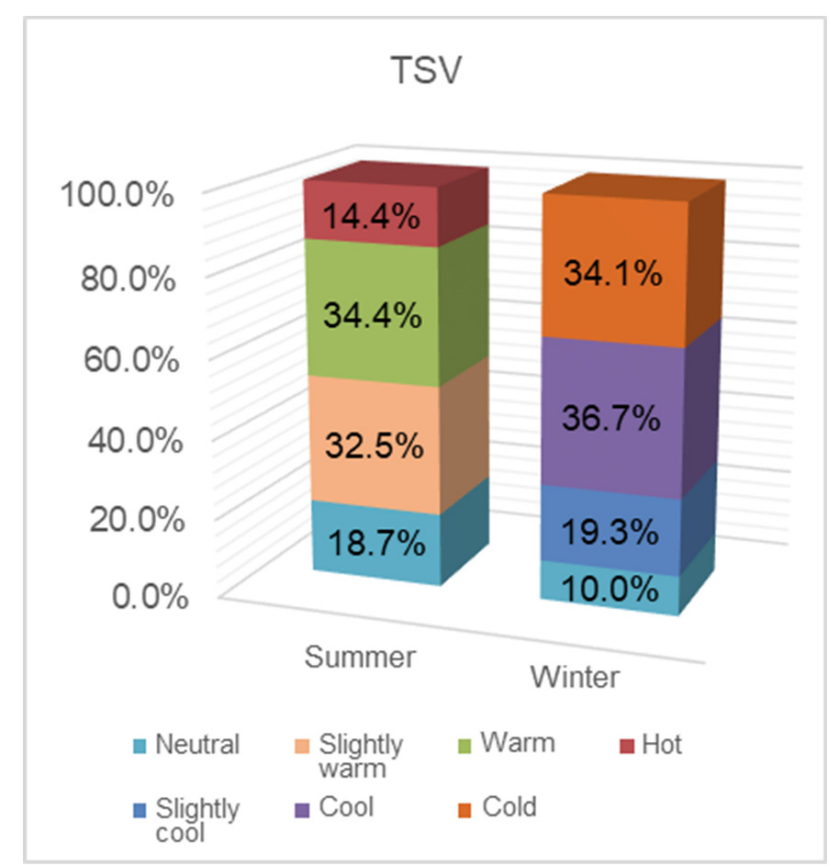

(b)

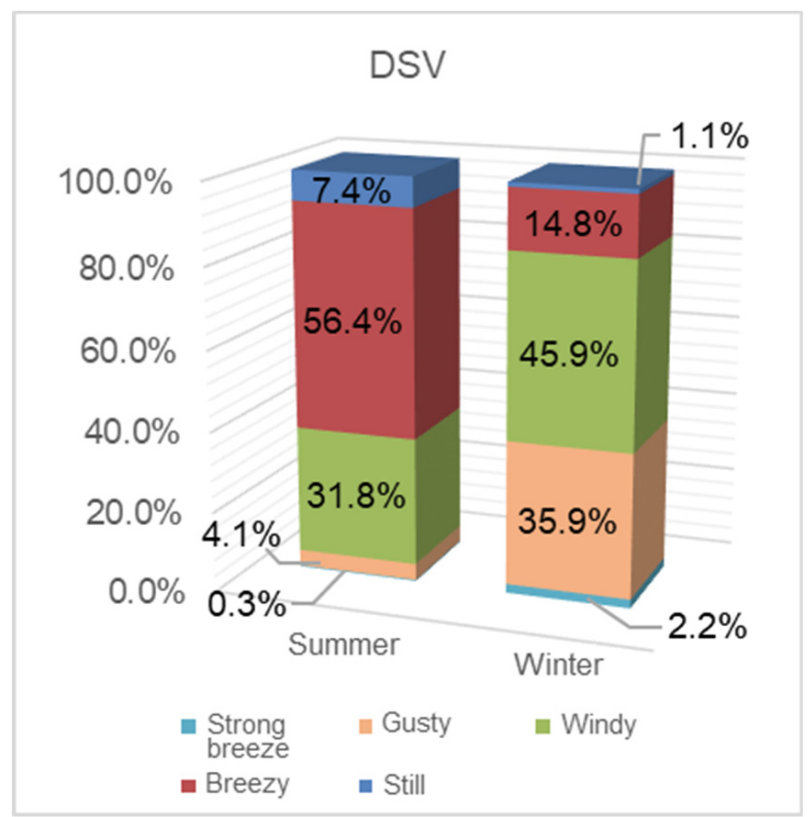

(d)

Figure 3. Statistical results of residents' thermal comfort voting in winter and summer. (a) The proportion of TCV in two seasons; (b) The proportion of TSV in two seasons; (c) The proportion of HSV in two seasons; (d) The proportion of DSV in two seasons.

According to the results for TCV, the comfort in winter is slightly better. The proportions of the votes for "very comfortable" and "comfortable" account for $48.1 \%$ in winter, which is only $6.4 \%$ higher than $41.7 \%$ in summer. 
According to the results for TSV, the proportions of the total votes for "neutral" and "slightly warm" in summer respectively account for $18.7 \%$ and $32.5 \%$, which are $8.7 \%$ and $13.2 \%$ higher than $10.0 \%$ and $19.3 \%$ for "neutral" and "slightly cool", respectively, in winter. Hence, residents are more satisfied with the temperatures of the outdoor environments in summer, which has more appropriate thermal effects.

According to the results for HSV, "damp" and "very damp" together were $45.5 \%$ in summer, which is $18.1 \%$ higher than $27.4 \%$ in winter. "Damp" and "very damp" in summer are higher, indicating that summer feels more humid. According to Vanke Jing Yuan (no. h), the average humidity is $72.9 \%$ in summer and $57.8 \%$ in winter.

According to the measurements of wind speed, the average speeds are $0.88 \mathrm{~m} / \mathrm{s}$ in summer and $0.76 \mathrm{~m} / \mathrm{s}$ in winter, both of which are relatively low. As seen in the DSV chart, the proportions of votes for "breezy" and "still" in summer are 56.4\% and 7.4\%, respectively, whereas those in winter are $14.8 \%$ and $1.1 \%$, respectively, which are much lower. Therefore, residents are more likely to feel a slight or calmer wind in summer.

According to the temperature measurements, the average temperature in summer is $32.56^{\circ} \mathrm{C}$, which is high-temperature weather [40] and is $7.71^{\circ} \mathrm{C}$ in winter, which accords with the eighth grade of low-temperature degrees established by prior meteorological studies [41]. According to the results for TCV, residents are more satisfied with the overall outdoor thermal comfort in winter, but the proportion of the votes for moderate comfort in summer is $44.8 \%$, which is $8.1 \%$ more than $36.7 \%$ in winter. Hence, residents are better able to tolerate the outdoor environment in summer. According to the frequencies of daily outdoor activities, the proportion in summer is $50.5 \%$, which is $10.9 \%$ higher than $39.6 \%$ in winter.

\subsection{Influences of Planning Characteristics on Thermal Comfort in Summer}

The influences of building height, building density, and environmental quality on outdoor thermal comfort in the summer were examined. Since high-temperature weather are defined as days with maximum temperatures above $32{ }^{\circ} \mathrm{C}$ [40], the questionnaire samples under the condition of measuring temperature $(\mathrm{Ta})$ greater than $32{ }^{\circ} \mathrm{C}$ were selected.

3.2.1. Increasing Building Height Can Improve Outdoor Thermal Comfort and Humidity Satisfaction within Summer

According to the TCV diagram for summer, which are shown in Figure 4, the higher buildings result in higher levels of comfort in high-temperature weather. High-rise residential areas with buildings of more than 15 stories have the highest comfort in summer with a satisfaction value of $51.0 \%$, which is $25.6 \%$ higher than the $25.4 \%$ for low-rise communities. In areas with building heights of 8 stories and above, the number of residents who vote "very comfortable" and "comfortable" increase and reach at the range of $33.3-66.7 \%$, i.e., moderate comfort.

In the other three statistical charts, the comfort for areas with different building heights is mainly related to humidity in high-temperature summers. In the summer TSV and DSV charts, the satisfaction values for temperature and wind speed are relatively close. In the summer HSV chart, the satisfaction for humidity in high-rise areas is the highest at $55.6 \%$, which corresponds best to the comfort in high-rise areas. In addition, the proportions of residents who voted "damp" and "very damp" were $41.5 \%$ in low-, $35.8 \%$ in middle-high-, and $19.2 \%$ in high-rise areas. Hence, higher buildings correlated to fewer votes for damp conditions but more votes for higher comfort. In conclusion, increasing building height can improve the overall comfort while reducing the sense of humidity in higher-temperature summers but does not affect satisfaction with outdoor temperature or wind speed. 


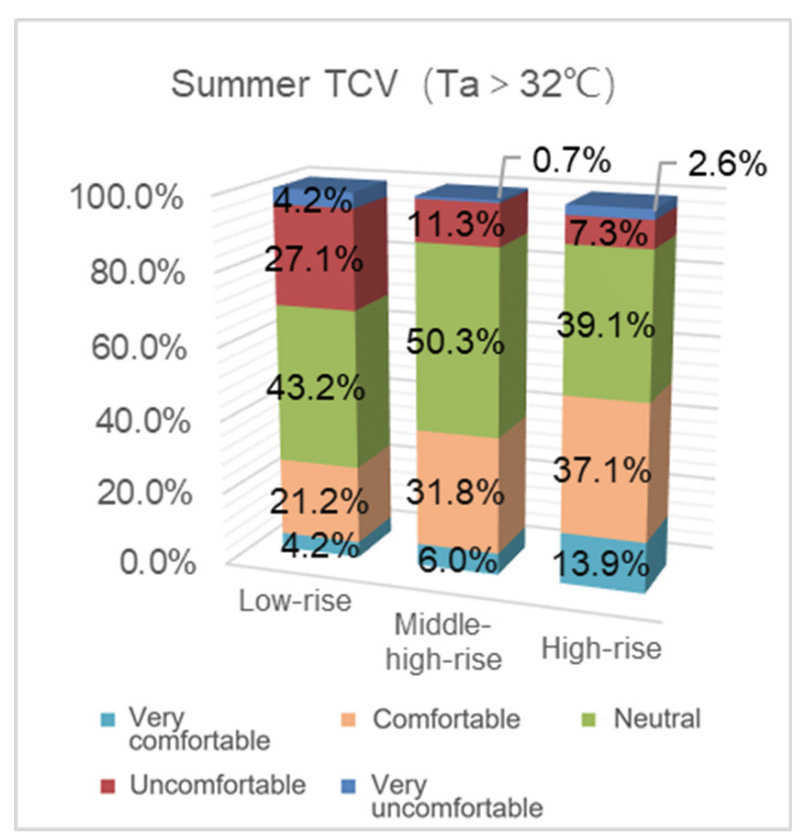

(a)

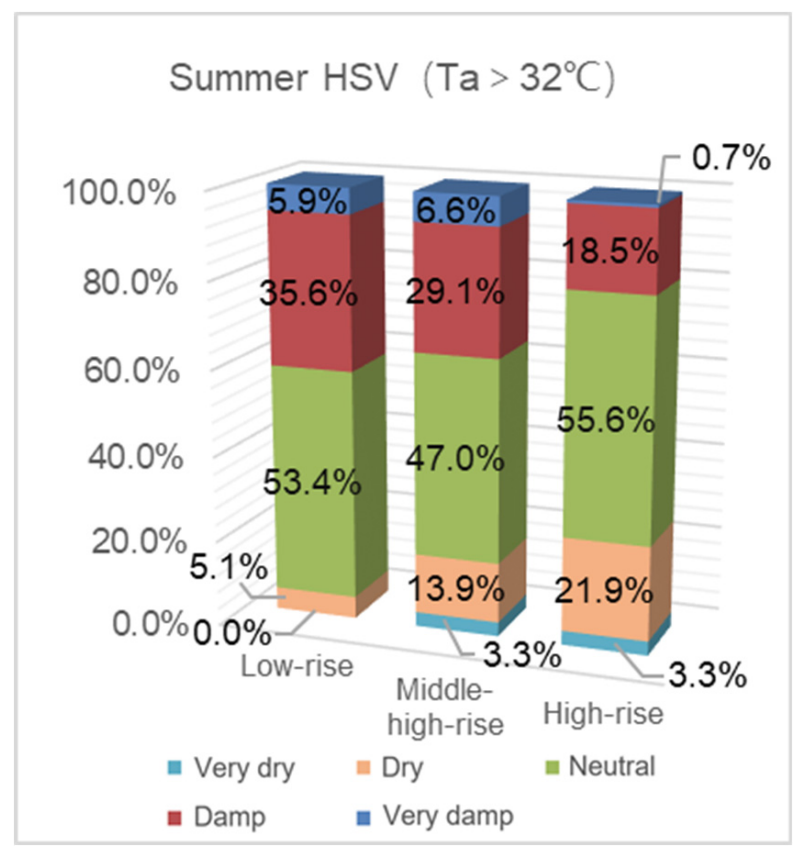

(c)

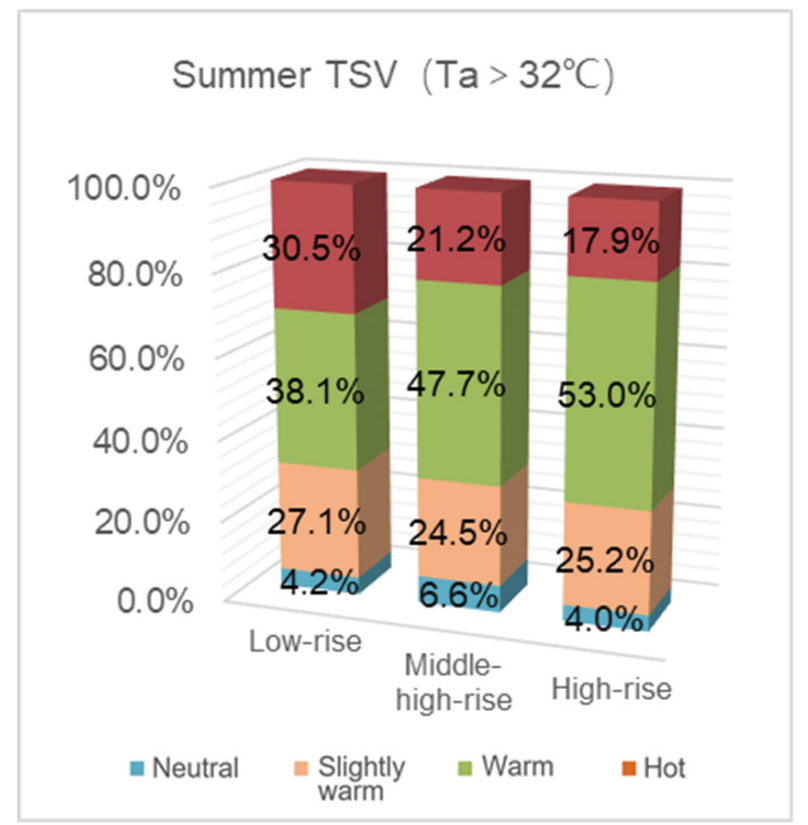

(b)

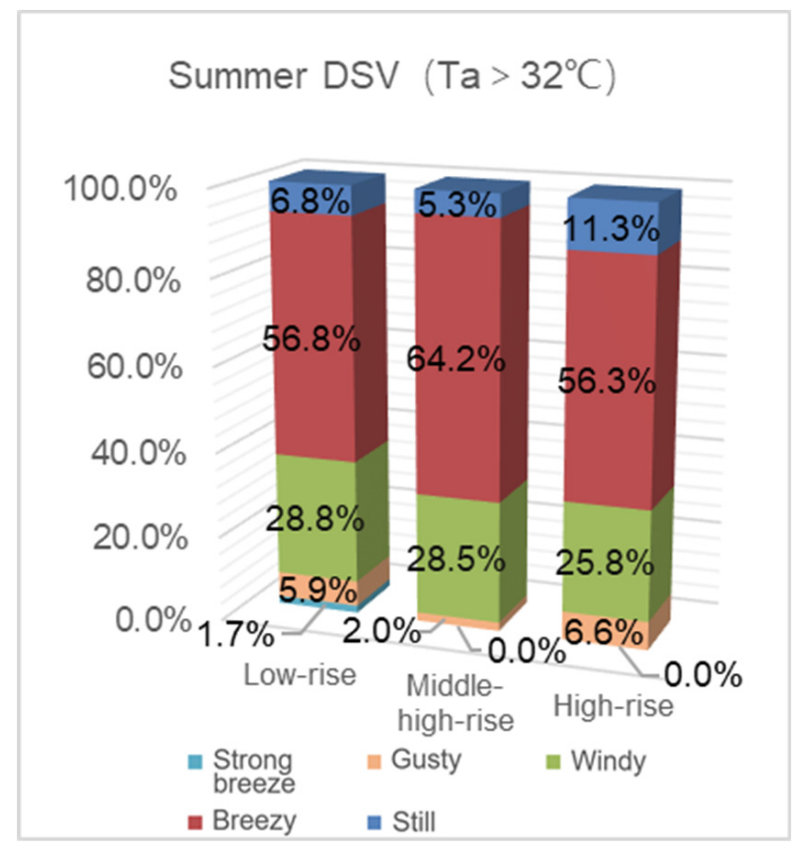

(d)

Figure 4. Voting results of summer thermal comfort for different building heights. (a) The proportion of TCV in summer; (b) The proportion of TSV in summer; (c) The proportion of HSV in summer; (d) The proportion of DSV in summer.

In high-temperature weather, low-rise areas feel hotter. The summer TSV chart shows that the temperature satisfaction for the three types of areas is close. The proportion of low-rise residents who feel very hot is the highest at $30.5 \%$. For example, in the low-rise Ban Qiao community (no. e), the buildings are mainly three-story townhouses. In hightemperature summers, only $1.6 \%$ of the residents feel "neutral", whereas $98.4 \%$ of the residents feel "slightly warm" and above. 
3.2.2. Medium Building Density Is Most Conducive to Outdoor Thermal Comfort and wind Speed Satisfaction in Summer

In high-temperature weather, outdoor comfort deriving from satisfaction with wind speed is high in residential areas with different building densities, which are shown in Figure 5. According to the summer TSV and HSV charts, satisfaction with the humidity and temperature is not the strongest in medium-density areas and does not correlate with the highest comfort in the medium-density ones. The levels of comfort of areas with different building densities are less affected by temperature and humidity. As seen in the summer DSV chart, the wind speeds in the high-density areas are the lowest, as 73.2\% of the residents feel slight or no wind. The satisfaction value of $35.2 \%$ for wind speed in the medium-density areas is the highest in summer and correlates with the highest level of comfort. Thus, wind speed is the main factor affecting outdoor comfort in areas with different building densities.

The summer TCV chart shows that outdoor comfort for medium-density areas in high-temperature summers is the highest at a satisfaction value of $50.8 \%$, which is $20.2 \%$ higher than the lowest value at $30.6 \%$ in low-density areas. For example, Vanke City Garden (No. g) and Fo Zu Ling Community (No. i) have similar average building heights of 21.9 and $22.1 \mathrm{~m}$, respectively, but differing building densities of $24 \%$ (medium) and $21 \%$ (low), respectively, and resulting comfort levels of $59.2 \%$ and $32.6 \%$, respectively. The difference between the comfort levels is $26.6 \%$.

\subsubsection{Relationship between Environmental Quality and Outdoor Comfort in Summer}

According to the summer TCV chart, which are shown in Figure 6, the overall outdoor thermal comfort of high-quality residential areas in high-temperature summers is the highest with satisfaction values of $50.8 \%$ for "very comfortable" and "comfortable" together, but that of low-quality areas is $25.5 \%$ lower at $25.3 \%$, so comfort is the lowest here. For example, Vanke Jing Yuan (No. h), a high-quality area, is equipped with inter-house green areas and supporting facilities while the ground pavements consist mostly of permeable rubber runways and floor tiles. This area's comfort level reaches 53.3\%. In contrast, Gang Hua Village (No. b) is a residence with older industrial workers and has many trees, but the ground is bare and consists of hard paving. The area lacks assisted living facilities, so it is a low-quality area with a comfort level of only $23.7 \%$.

According to the summer TSV chart, the temperature satisfaction is $6.0 \%, 4.7 \%$, and $3.9 \%$ in the low-, medium-, and high-quality residential areas, respectively. The values are close to each other and very low, but those for the high-quality areas contradict the assumption that they have the highest comfort.

According to the auxiliary analysis of the other charts, the proportions of the three areas with neutral outdoor humidity in the summer HSV chart are similar, On the other hand, those proportions who voted "damp" and "very damp" with 37.3\%, 25.2\%, and $29.7 \%$ for the low-, medium-, and high-quality areas, respectively.

In the summer DSV chart, the wind speed satisfaction is $26.5 \%, 22.0 \%$, and $35.2 \%$ in the low-, medium, and high-quality areas, respectively. The low levels of comfort in the low-quality areas depend on high humidity, whereas the high levels in the high-quality ones benefit from sufficient wind speeds, both of which obviously have stronger influences than does the temperature. 


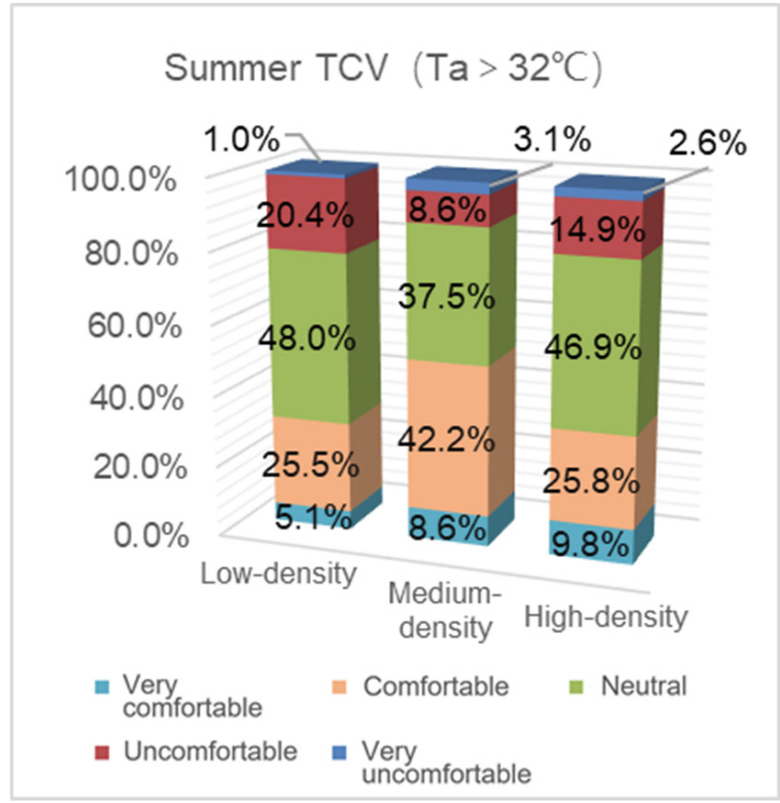

(a)

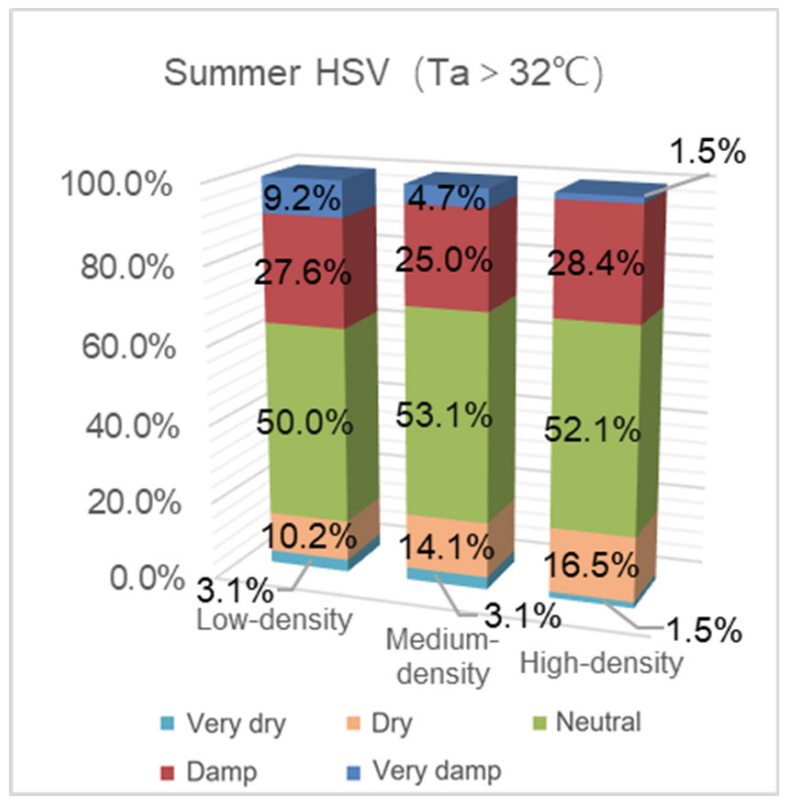

(c)

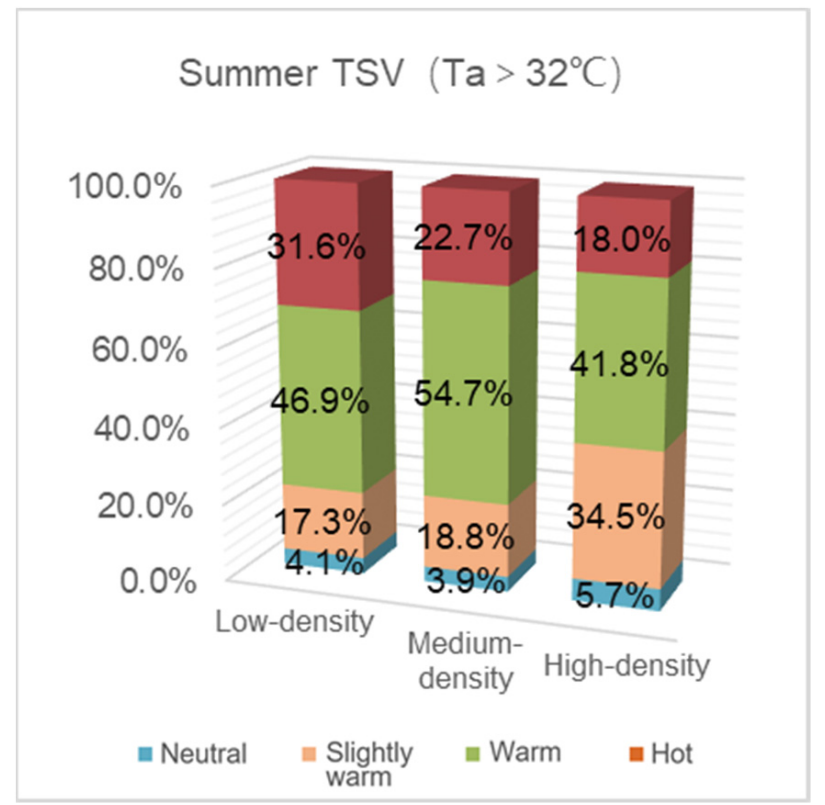

(b)

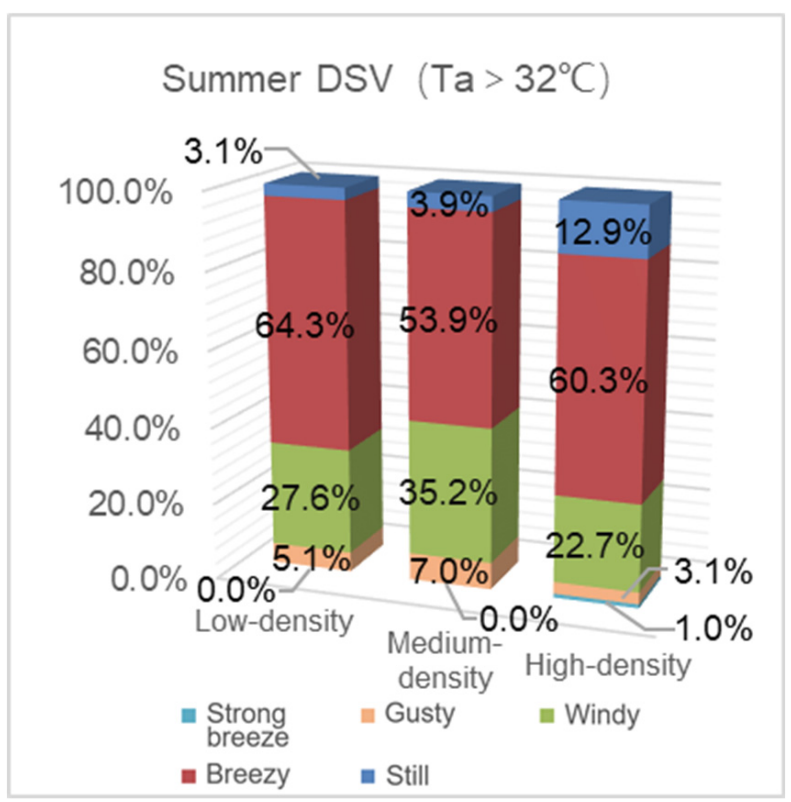

(d)

Figure 5. Voting results of summer thermal comfort in areas of different building densities. (a) The proportion of TCV in summer; (b) The proportion of TSV in summer; (c) The proportion of HSV in summer; (d) The proportion of DSV in summer. 


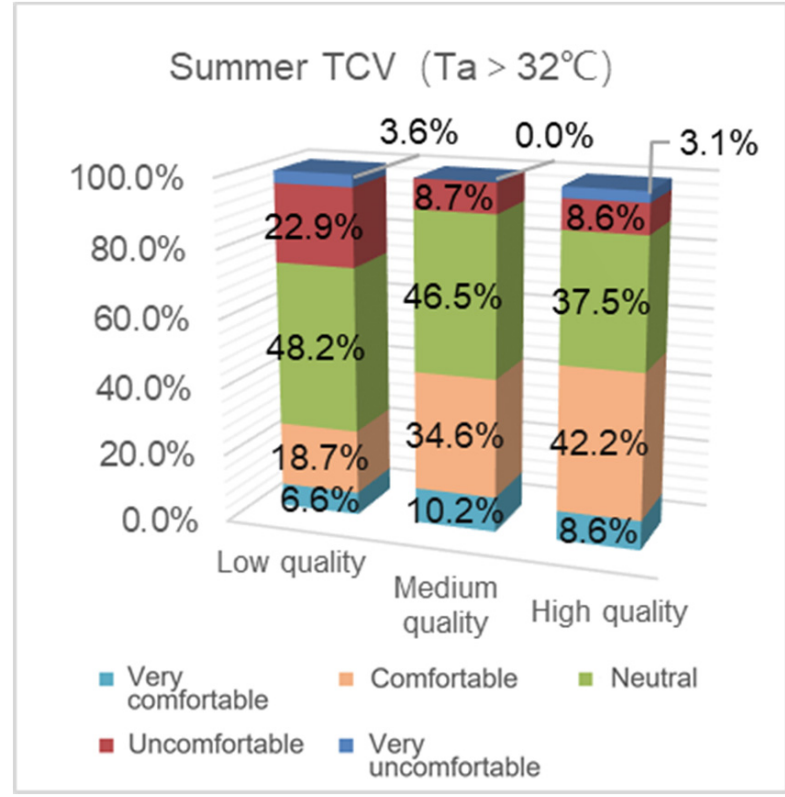

(a)

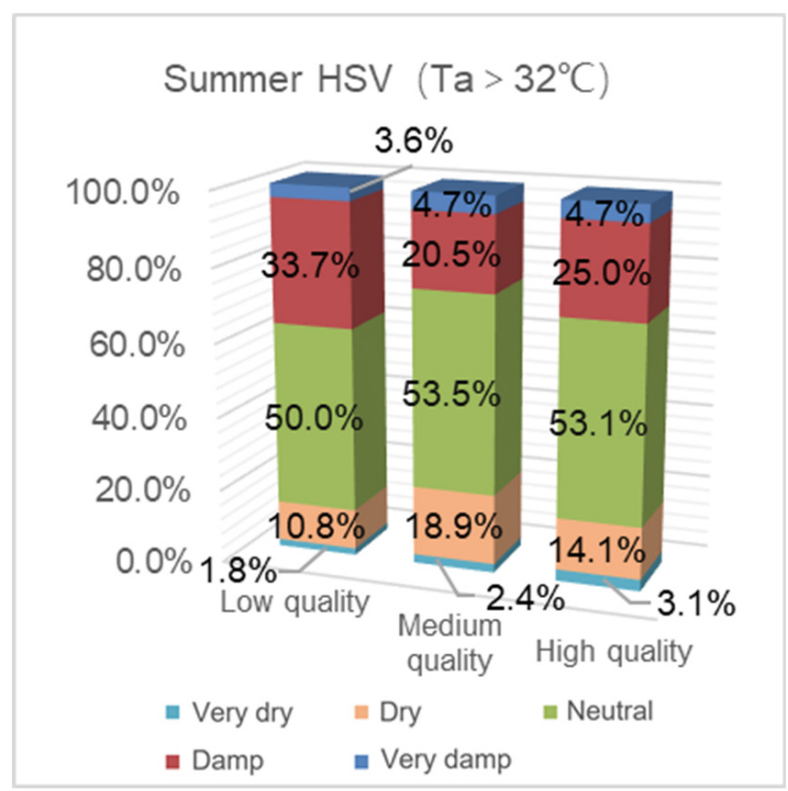

(c)

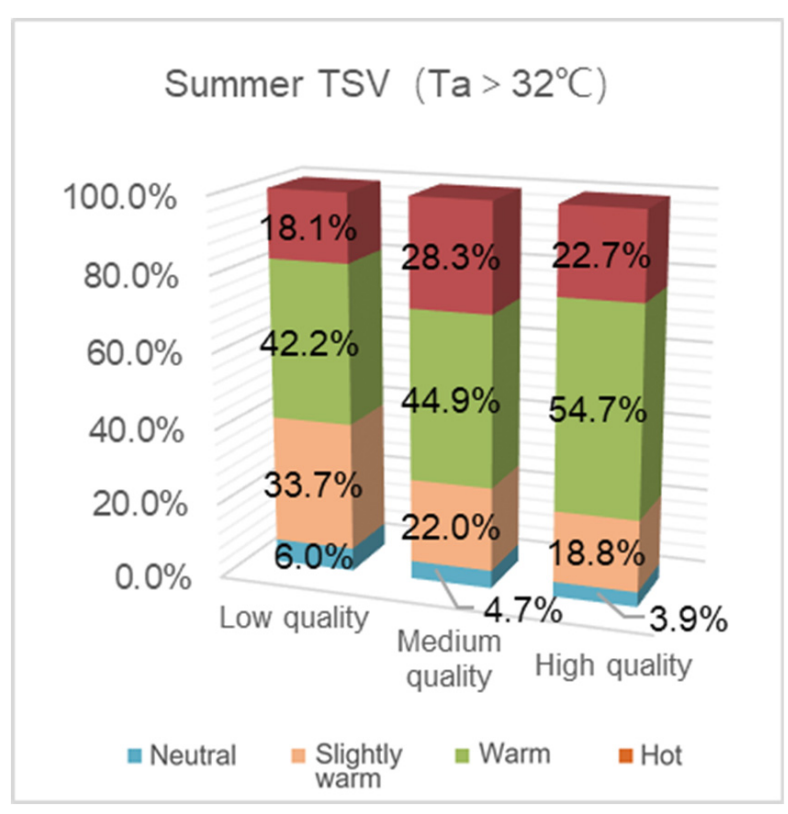

(b)

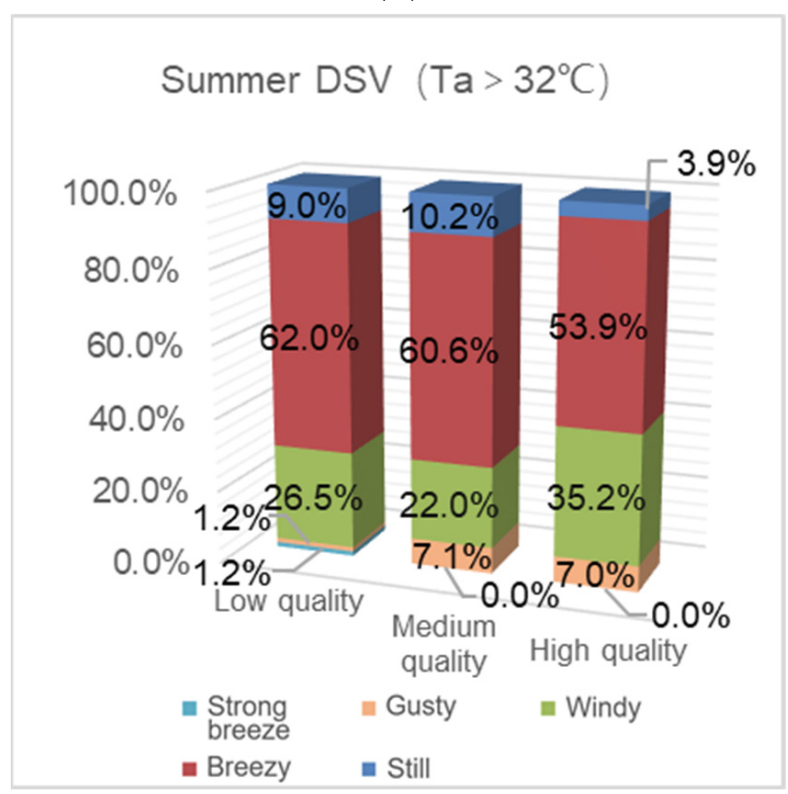

(d)

Figure 6. Voting results of summer thermal comfort in areas of different environment quality. (a) The proportion of TCV in summer; (b) The proportion of TSV in summer; (c) The proportion of HSV in summer; (d) The proportion of DSV in summer.

\subsection{Relationships between Outdoor Activities and Thermal Comfort}

As shown in Figure 7, the types of outdoor activities are affected by seasons.

Residents prefer static outdoor activities, such as chatting and resting, in summer but dynamic outdoor activities, such as fitness, in winter, whereas slow-paced activities, such as walking the dog and playing with children, are popular in both seasons. The first three categories in summer are walking the dog, chatting, and playing with children, which account for $24.0 \%, 20.1 \%$, and $15.4 \%$, respectively. In winter, walking the dog, playing with children, and fitness account for $21.0 \%, 18.4 \%$, and $18.3 \%$, respectively. In addition, the proportions of residents who chose running and dancing in summer were $9.3 \%$ and $2.6 \%$ respectively, which increased significantly in winter to $15.6 \%$ and $10.0 \%$, respectively. 


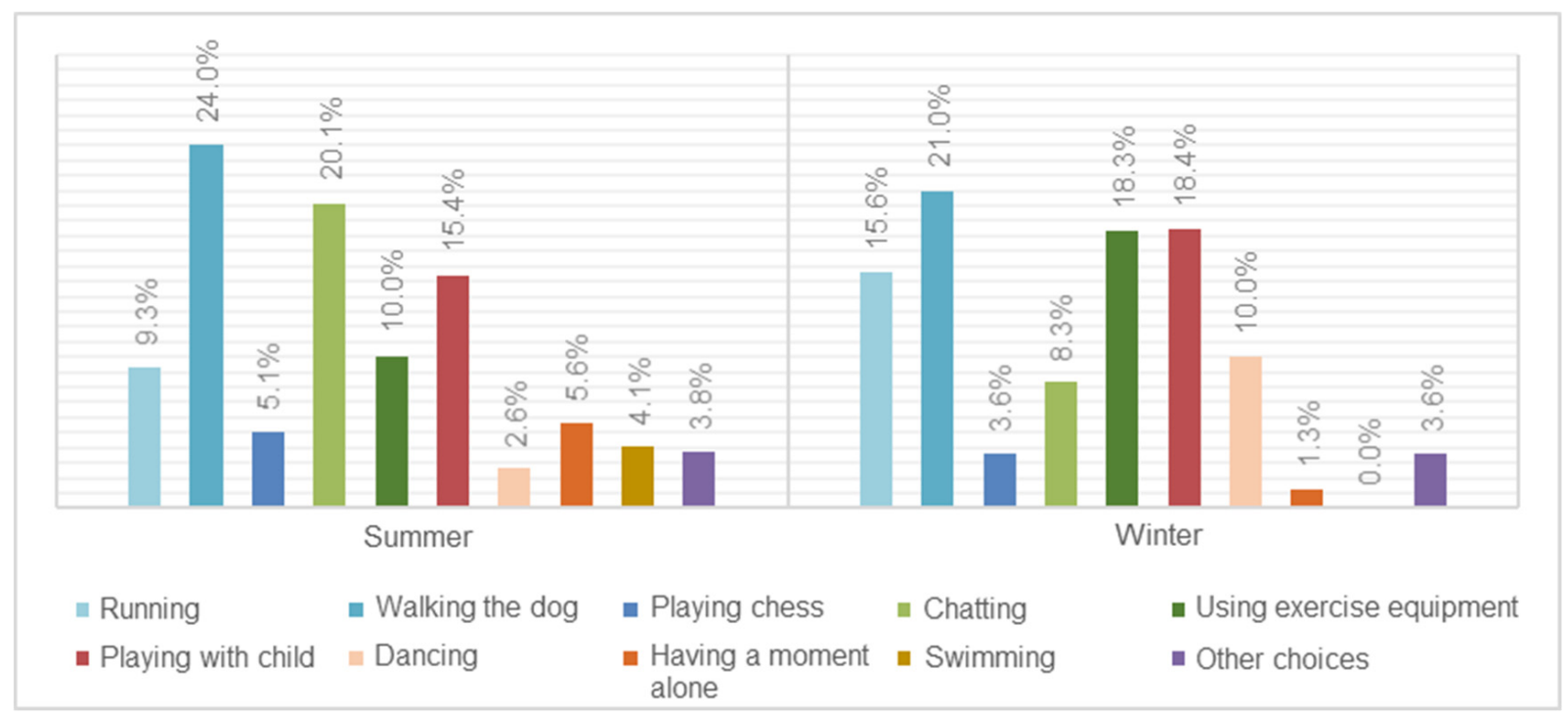

Figure 7. Selection of outdoor activity types for residents in summer and winter.

Residents can freely adjust the intensities of their activities according to the thermic needs of their bodies. The slow-paced activities do not generate much body heat. The sum proportions of walking the dog and playing with a child in both seasons are $39.4 \%$, so slow-paced activities are very popular in both seasons. Trails and children's playgrounds should be designed with sufficient sunshade and ventilation for summer while sun and wind shielding should be provided for in winter. Resting spots should be provided with shading and ventilation in summer. Fitness spots should need be designed to receive more sunlight and avoid winds directions in winter.

\subsection{Effects of Underlying Surface Types on Outdoor Thermal Comfort in Summer}

Spearman correlation analyses (Table 5) were conducted for the various underlying surfaces measured by the summer sample points and the mean thermal comfort vote (MTCV), mean temperature sensation vote (MTSV), mean humidity sensation vote (MHSV), and mean wind sensation vote (MDSV), respectively, to explore the main underlying surface types that affect comfort in summer.

Table 5. Spearman correlation analyses between outdoor underlying surfaces and voting in summer.

\begin{tabular}{llcccc}
\hline & & Green Area & Water Area & Area with Impervious Paving \\
\hline & \multirow{4}{*}{ MTCV } & Correlation coefficient & $0.812^{*}$ & -0.593 & -0.762 \\
& & Significance (double-tailed) & 0.008 & 0.092 & 0.017 \\
\multirow{4}{*}{ Rho of Spearman } & Correlation coefficient & $-0.857^{*}$ & 0.309 & $0.857^{*}$ \\
& \multirow{2}{*}{ MTSV } & Significance (double-tailed) & 0.003 & 0.418 & 0.003 \\
& & Correlation coefficient & 0.586 & 0.091 & -0.653 \\
& \multirow{2}{*}{ MHSV } & Significance (double-tailed) & 0.097 & 0.815 & 0.057 \\
& & Correlation coefficient & 0.479 & -0.653 & -0.479 \\
& MDSV & Significance (double-tailed) & 0.192 & 0.056 & 0.192 \\
\hline
\end{tabular}

* The correlation was significant at 0.01 level (double tail).

Each type of underlying surface in the same range affects the thermal comfort of residents differently in summer. A positive correlation exists between green areas and MTCV with a correlation coefficient of $r=0.812$, i.e., expanding green areas will improve thermal comfort. A negative correlation exists between these areas and MTSV with a correlation coefficient of $r=-0.857$, i.e., the expansion would reduce the temperature sensation. A positive correlation exists between areas with impervious paving and MTSV with a correlation coefficient of $r=0.857$, i.e., expanding the areas would increase the 
temperature sensation. No correlation exists with the other variables at a significance level of 0.01 .

Green areas and those with impervious paving are the main underlying surface types that affect outdoor thermal comfort in summer. Expanding the former is beneficial to both comfort and temperature sensations, whereas reducing the latter is beneficial only to temperature sensations. According to the measurements at each sample point, if the green coverage rate exceeds $70.0 \%$ in the research area of $25 \mathrm{~m} \times 25 \mathrm{~m}$, then the temperature satisfaction can be increased to $33.3 \%-66.7 \%$, thus improving overall comfort. If the paved areas are larger than $400 \mathrm{~m}^{2}$, then the temperature satisfaction would be less than $21.5 \%$. Compared with the soft decorations of the grassland areas, paved areas have higher light reflectivity, which raises the ground temperature [42] and increases thermal sensations.

As per design recommendations, the green areas should be increased. For example, expanding lawn areas could reduce temperature sensations in summer without reducing the wind speed at the height of pedestrians. In winter, the proportion of residents who participate in activities on lawns, which is the second choice after open squares, could be as high as 24.5\%. Expanding lawns could provide more locations for outdoor activities. The numbers of low shrubs planted in winter on the windward sides of each site would also increase, thus reducing the heat in summer and the wind speeds in winter.

\section{Discussion}

Our field survey and data analysis allow us to offer some guidelines for outdoor space planning and design to improve thermal comfort. However, some of the findings should be further discussed first.

\subsection{Analysis of Current Conditions of Outdoor Thermal Comfort in Winter and Summer}

In high-temperature summer, residents need to reduce the intensities of their physical activities while increasing their use of handheld fans and other physical measures to cool themselves. The thermal reduction effect is not obvious. In winter, residents can quickly and effectively keep warm by wearing the appropriate clothing, increasing the intensities of their activities, and looking for well-lit venues. When the human body is unable to respond to cold and hot environments effectively, then it must adapt physically or psychologically [43]. Although the comfort in summer is worse than that in winter, residents prefer to go out in summer. Residents are better able to tolerate the outdoor environment in summer.

The precipitation in Wuhan is concentrated and the evaporation of water is easier in summer, so the air is more humid [44]. The denser vegetation in this season also has a humidifying effect [45], so the outdoor environment is wetter than in winter.

The wind direction in Wuhan is mainly southerly in summer but northerly in winter [44]. However, most of the buildings are arranged in east-west directions, blocking the main winds in both seasons. Such an arrangement is conducive to the wind sensations in winter but not in summer. Excessively low wind speeds are more obvious in summer.

\subsection{Analysis of Relationships between Characteristics of Residential Areas and Thermal Comfort in Summer}

(1). Building height

Compared with the low-rise areas, the high-rise ones have longer distances between the residential buildings to meet the standard for sunshine, so outdoor spaces are larger and more conducive to the circulation of air and water molecules, thus reducing dampness in the high-temperature weather. Therefore, the overall comfort and humidity satisfaction are highest in high-rise areas, whereas the outdoor thermal and humidity sensations are the highest in the low-rise ones. The layout of buildings in Wuhan hinders the main southerly winds, so the three residential areas receive less wind. Hence, building height has little influence on the wind sensation in summer. 


\section{(2). Building density}

E. L. Krüger et al. [46] proved that the correlation between the sky view factor (SVF) of an outdoor and its mean radiation temperature (MRT) was $0.75\left(R^{2}=0.57\right)$. Lower densities increase the SVFs and allow for more thermal radiation, which creates hotter outdoor environments. Higher densities block the wind more effectively. According to Tetsu Kubota et al. [47], every $1 \%$ increase in density reduces wind speed by $0.01 \mathrm{~m} / \mathrm{s}$. Therefore, outdoor thermal sensations are higher in low-density areas, whereas wind sensations are lower in high-density ones.

(3). Environmental quality

The higher-quality areas have better public facilities, green configurations, and ground pavements. The building densities are moderate, only a few sunny spaces are available and the wind shielding effects are lower than the high-density buildings. The height of the outdoor vegetation is conducive to the ventilation of pedestrians. Therefore, the overall outdoor comfort and wind sensations are higher in areas with high environmental quality.

\subsection{Selection of Outdoor Activities}

Studies have shown that heat sensations are more sensitive in winter [48], so less intensive activities, such as walking the dog and playing with children, are more frequent in summer. However, sitting and chatting in winter would quickly reduce people's somatosensory temperatures, so they would try as much as possible to reduce the number of static activities in order to maintain their body temperatures.

\subsection{Limitations}

This study has some shortcomings. Due to limited time, only nine typical areas with planned environments and geographical locations could be studied. By the influence research of planning parameters and meteorological parameters, this study mainly focuses on the subjective feelings of residents on the thermal environment. In the next step, more residential areas and objective conditions of individual residents such as clothing, gender and age should be examined in depth. Thermal radiation is also an important meteorological parameter. Due to the limitations of experimental instruments and measurement conditions, common indexes such as temperature, relative humidity and wind speed are mainly selected in this study. The comprehensiveness of meteorological parameters needs to be strengthened in future research.

\section{Conclusions}

This study selected nine residential areas in Wuhan, a city with typically hot summer and cold winter seasons, as the research object and investigated the subjective feelings that the residents experienced regarding their outdoor thermal comfort. First, we conducted a field survey with questionnaires and interviews of the residents, as well as on-site thermal measurements of environmental data and quantifications of spatial design elements. Then, we collated and analysed the data with the help of SPSS and Microsoft Excel software. Our main conclusions are as follows.

(1). The current levels of outdoor thermal comfort are different for each season. Although the difference between the comfort in both seasons is only $6.4 \%$, the other three indicators of temperature, humidity, and wind speed are quite different: Summer has a more appropriate thermal effect, but higher humidity, and significantly lower wind speed.

(2). Thermal comfort in summer is affected by building height, density and environmental quality. In temperatures above $32{ }^{\circ} \mathrm{C}$, the high-rise residential areas with more than 15 stories produce the highest outdoor comfort with a satisfaction value of $51.00 \%$, which is mainly the result of low humidity. Where the building density is $22 \%<$ FAR $\leq 30 \%$, the levels of comfort are the highest with a satisfaction value of $50.8 \%$, which is mainly the result of wind speeds. Moreover, in areas with high 
environmental quality, comfort is also the highest with a satisfaction value of $50.8 \%$, which is also mainly the result of higher wind speeds.

(3). The types of outdoor activities chosen by residents differ by season. Residents tend to choose static activities in summer but dynamic activities in winter. Spots for resting and sitting are more suitable for outdoor activities in summer, whereas spots for sports and fitness are more suitable in winter while footpaths and children's playgrounds are suitable in both seasons. The improvement of facilities enhances outdoor thermal comfort.

(4). Green areas and those with impervious paving can affect outdoor thermal comfort in summer. Positive correlations exist between green areas and comfort, so expanding such areas can reduce heat sensations. When the green coverage rate exceeds $70.0 \%$, temperature satisfaction can be increased from $33.3 \%$ to $66.7 \%$. Negative correlations exist between areas with impervious paving and temperature sensations. If such areas are $400-625 \mathrm{~m}^{2}$, then the temperature satisfaction drops to less than $21.5 \%$.

The above results can provide a reference for the study of the outdoor thermal comfort in other urban residential areas during both seasons, as well as provide a basis for community planning and improving urban living environments.

Author Contributions: Conceptualization, K.L.; methodology, K.L. and T.X.; software, K.L. and W.L.; validation, K.L. and W.L.; formal analysis, K.L.; investigation, T.X. and W.L.; resources, K.L. and T.X.; data curation, K.L. and W.L.; writing-original draft preparation, K.L., T.X. and W.L.; writing-review and editing, K.L. and W.L.; supervision, K.L.; project administration, K.L.; funding acquisition, K.L. All authors have read and agreed to the published version of the manuscript.

Funding: This research was funded by the Basic Work of Science and Technology of China, grant number 2013FY112500, and the National Natural Science Foundation of China, grant number 51208389.

Data Availability Statement: Except for the quotation noted, the data are from the authors' own measurements and surveys.

Conflicts of Interest: The authors declare no conflict of interest.

$\begin{array}{ll}\text { Abbreviations } \\ \text { TCV } & \text { Thermal comfort voting } \\ \text { PMV } & \text { Predicted mean vote } \\ \text { SET } & \text { Standard effective temperature } \\ \text { UTCI } & \text { Universal thermal climate index } \\ \text { PET } & \text { Physiological equivalent temperature } \\ \text { CFD } & \text { Computational fluid dynamics } \\ \text { FAR } & \text { Floor area ratio } \\ \text { TSV } & \text { Temperature sensation voting } \\ \text { HSV } & \text { Humidity sensation voting } \\ \text { DSV } & \text { Draft sensation voting } \\ \text { MTCV } & \text { Mean thermal comfort vote } \\ \text { MTSV } & \text { Mean temperature sensation vote } \\ \text { MHSV } & \text { Mean humidity sensation vote } \\ \text { MDSV } & \text { Mean wind sensation vote } \\ \text { SVF } & \text { Sky view factor } \\ \text { MRT } & \text { Mean radiation temperature }\end{array}$

\section{Appendix A}

Table A1. basic current conditions and sample points of residential areas. 


\begin{tabular}{|c|c|c|c|c|c|c|c|}
\hline Label & Name & $\begin{array}{c}\text { Building Height in } \\
\text { Stories }\end{array}$ & $\begin{array}{l}\text { Average building } \\
\text { Height in Metres }\end{array}$ & Building Density & Floor Area Ratio & $\begin{array}{l}\text { Year of Completed } \\
\text { Construction }\end{array}$ & Characteristics \\
\hline $\mathrm{a}$ & Oriental Hawaii Villa & 3,4 & 8.4 & $21 \%$ & 0.63 & 2003 & $\begin{array}{l}\text { Most of the buildings are } \\
\text { townhouses and single-family } \\
\text { villas. The planning takes the } \\
\text { water system as the centre and } \\
\text { arranges the driveway around } \\
\text { the residential area. Greening is } \\
\text { uneven and the ground is hard. }\end{array}$ \\
\hline
\end{tabular}

Investigation sample point

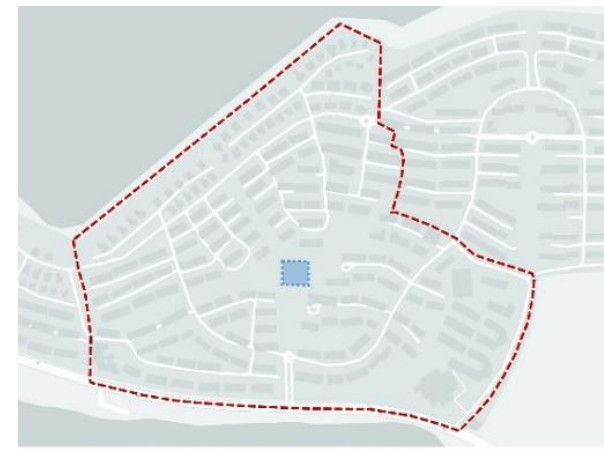

I..." Sample point ----- Residential area

\begin{tabular}{|c|c|c|c|c|c|c|c|}
\hline Label & Name & $\begin{array}{c}\text { Building Height in } \\
\text { Stories }\end{array}$ & $\begin{array}{l}\text { Average Building } \\
\text { Height in Metres }\end{array}$ & Building Density & Floor Area Ratio & $\begin{array}{l}\text { Year of Completed } \\
\text { Construction }\end{array}$ & Characteristics \\
\hline $\mathrm{b}$ & Gang Hua Village & 6 & 16.8 & $33 \%$ & 1.98 & 1992 & $\begin{array}{l}\text { Housing for senior industrial } \\
\text { workers. There are many tall } \\
\text { evergreen trees and the space } \\
\text { under the forest is covered with } \\
\text { bare, hard ground. Lack of } \\
\text { assisted living facilities. some } \\
\text { areas have benches, pavilions, } \\
\text { and newsstands. }\end{array}$ \\
\hline
\end{tabular}


Investigation sample point

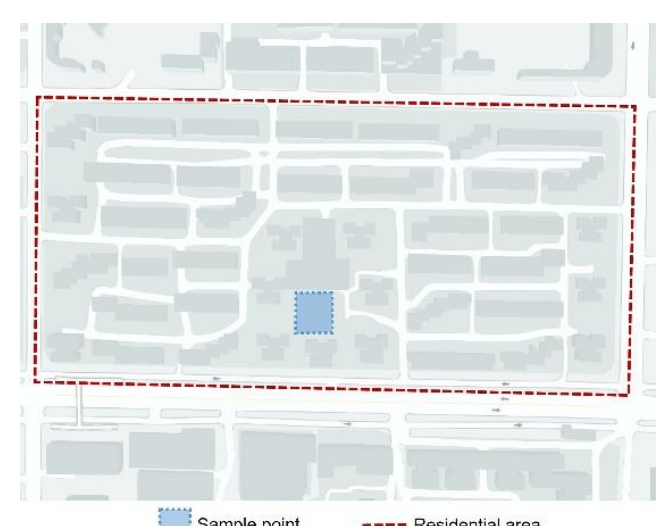

Sample point ---- Residential area

\begin{tabular}{|c|c|c|c|c|c|c|c|}
\hline Label & Name & $\begin{array}{l}\text { Building Height in } \\
\text { Stories }\end{array}$ & $\begin{array}{l}\text { Average Building } \\
\text { Height in Metres }\end{array}$ & Building Density & Floor Area Ratio & $\begin{array}{l}\text { Year of Completed } \\
\text { Construction }\end{array}$ & Characteristics \\
\hline c & $\begin{array}{l}\text { Zhang Jia Wan } \\
\text { Community }\end{array}$ & $6,8,11,18$ & 22.8 & $24 \%$ & 2.5 & 1994 & $\begin{array}{l}\text { Affordable housing. Many tall, } \\
\text { evergreen trees and equipped } \\
\text { with flower beds, shrubs, etc. } \\
\text { Cool in summer and lack of } \\
\text { sunshine in winter. Equipped } \\
\text { with fitness facilities, benches, } \\
\text { pavilions, etc. }\end{array}$ \\
\hline
\end{tabular}

Investigation sample point

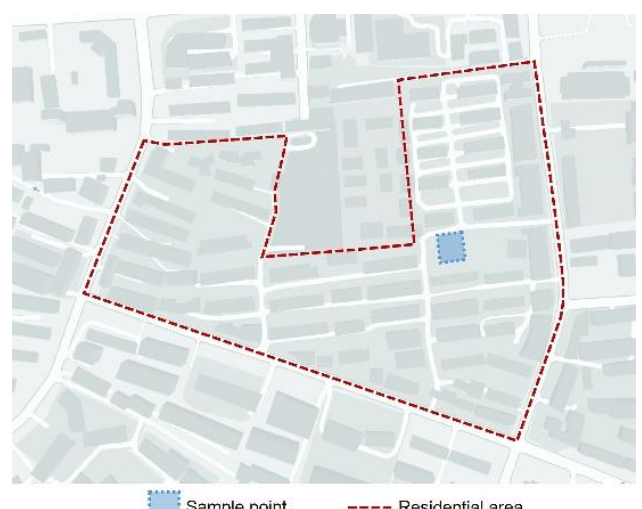

Sample point _---- Residential area 


\begin{tabular}{|c|c|c|c|c|c|c|c|}
\hline Label & Name & $\begin{array}{c}\text { Building Height in } \\
\text { Stories }\end{array}$ & $\begin{array}{l}\text { Average Building } \\
\text { Height in Metres }\end{array}$ & Building Density & Floor Area Ratio & $\begin{array}{c}\text { Year of Completed } \\
\text { Construction }\end{array}$ & Characteristics \\
\hline d & $\begin{array}{l}\text { Central Garden } \\
\text { Residential Area }\end{array}$ & $6,8,17$ & 23.4 & $32 \%$ & 2.1 & 2003 & $\begin{array}{l}\text { A pleasant living environment } \\
\text { with a central green space and } \\
\text { scattered arrangements of trees, } \\
\text { shrubs, and grasslands. Walking } \\
\text { trails in the forest. Equipped } \\
\text { with day-care centres, shopping } \\
\text { malls, and swimming pools. }\end{array}$ \\
\hline
\end{tabular}

Investigation sample point

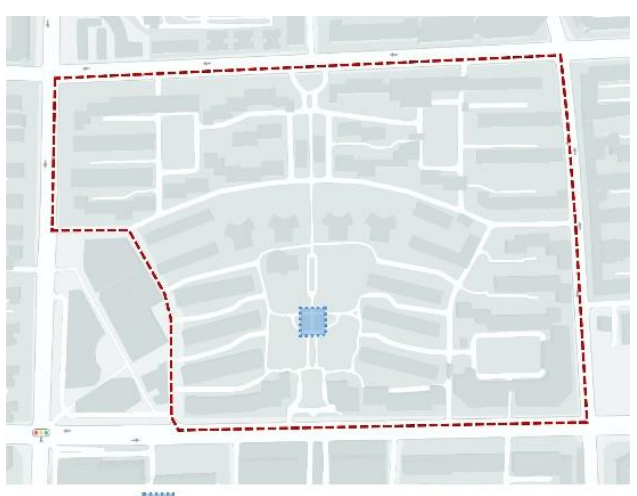

Sample point ---- Residential area

\begin{tabular}{|c|c|c|c|c|c|c|c|}
\hline Label & Name & $\begin{array}{c}\text { Building Height in } \\
\text { Stories }\end{array}$ & $\begin{array}{l}\text { Average Building } \\
\text { Height in Metres }\end{array}$ & Building Density & Floor Area Ratio & $\begin{array}{l}\text { Year of Completed } \\
\text { Construction }\end{array}$ & Characteristics \\
\hline e & Ban Qiao Community & 3 & 8.4 & $42 \%$ & 1.23 & 2002 & $\begin{array}{l}\text { Rebuilt houses arranged in rows } \\
\text { with narrow spacing. Lack of } \\
\text { greening and public activity } \\
\text { spaces while the ground is hard } \\
\text { pavement. }\end{array}$ \\
\hline
\end{tabular}


Investigation sample point

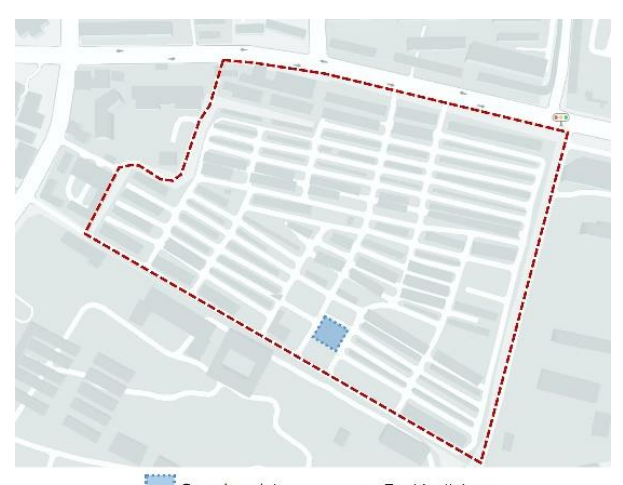

\begin{tabular}{|c|c|c|c|c|c|c|c|}
\hline Label & Name & $\begin{array}{c}\text { Building Height in } \\
\text { Stories }\end{array}$ & $\begin{array}{l}\text { Average Building } \\
\text { Height in Metres }\end{array}$ & Building Density & Floor Area Ratio & $\begin{array}{l}\text { Year of Completed } \\
\text { Construction }\end{array}$ & Characteristics \\
\hline $\mathrm{f}$ & $\begin{array}{l}\text { Hong Jing Garden } \\
\text { Villa }\end{array}$ & 2,3 & 9.0 & $18 \%$ & 0.55 & 1995 & $\begin{array}{l}\text { Most of the buildings are } \\
\text { single-family houses and } \\
\text { townhouses of uniform height. } \\
\text { Trees and shrubs are distributed } \\
\text { at different levels between } \\
\text { houses, but there is a lack of } \\
\text { public spots for outdoor } \\
\text { activities. }\end{array}$ \\
\hline
\end{tabular}

Investigation sample point

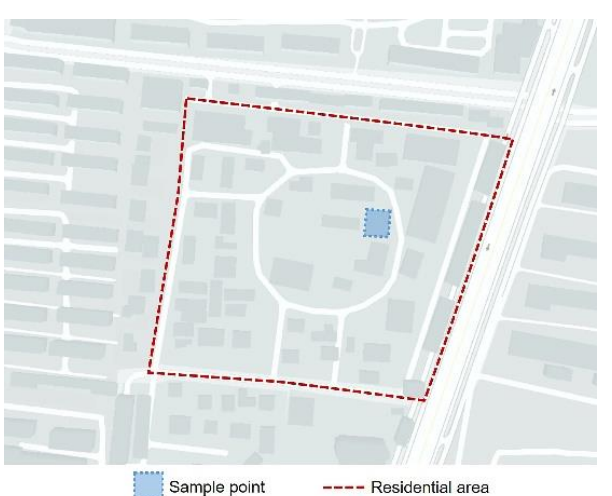




\begin{tabular}{|c|c|c|c|c|c|c|c|}
\hline Label & Name & $\begin{array}{c}\text { Building Height in } \\
\text { Stories }\end{array}$ & $\begin{array}{l}\text { Average Building } \\
\text { Height in Metres }\end{array}$ & Building Density & Floor Area Ratio & $\begin{array}{l}\text { Year of Completed } \\
\text { Construction }\end{array}$ & Characteristics \\
\hline $\mathrm{g}$ & $\begin{array}{l}\text { Vanke City Garden } \\
\text { Residential Area }\end{array}$ & $4,6,7,10$ & 21.9 & $24 \%$ & 1.3 & 2007 & $\begin{array}{l}\text { The community takes commerce } \\
\text { as its centre and the road as the } \\
\text { basis for configuring residential } \\
\text { groups. The greening is evenly } \\
\text { distributed with sidewalks } \\
\text { under the trees, benches along } \\
\text { the road, and facilities for the } \\
\text { disabled. }\end{array}$ \\
\hline
\end{tabular}

Investigation sample point

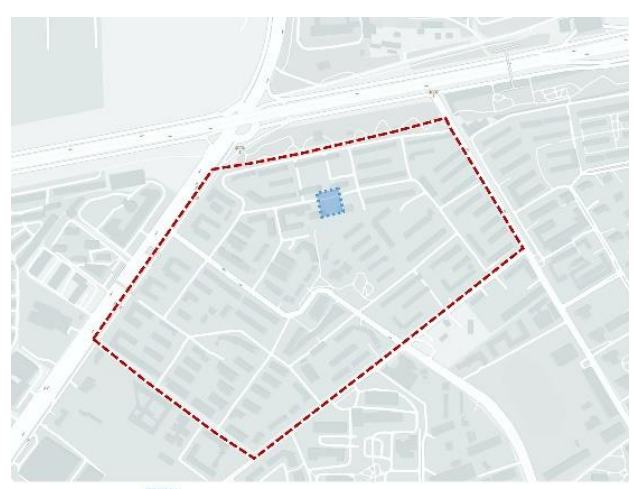

Sample point ---- Residential are

\begin{tabular}{|c|c|c|c|c|c|c|c|}
\hline Label & Name & $\begin{array}{c}\text { Building Height in } \\
\text { Stories }\end{array}$ & $\begin{array}{l}\text { Average Building } \\
\text { Height in Metres }\end{array}$ & Building Density & Floor Area Ratio & $\begin{array}{l}\text { Year of Completed } \\
\text { Construction }\end{array}$ & Characteristics \\
\hline $\mathrm{h}$ & $\begin{array}{l}\text { Vanke Jing Yuan } \\
\text { Residential Area }\end{array}$ & 34 & 90.0 & $25 \%$ & 4.57 & 2015 & $\begin{array}{l}\text { Super high-rise residential } \\
\text { buildings. Vegetation is mostly } \\
\text { trees around the house and the } \\
\text { central lawn. The open square is } \\
\text { equipped with fitness } \\
\text { equipment and benches. There } \\
\text { are no driveways and the } \\
\text { ground is paved with rubber } \\
\text { runway and floor tiles. }\end{array}$ \\
\hline
\end{tabular}


Investigation sample point

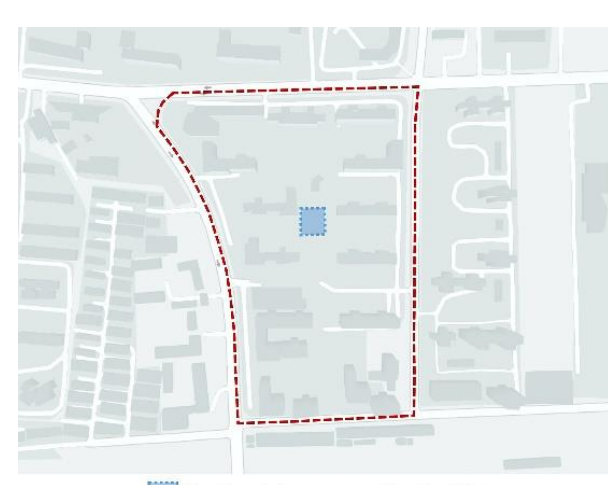

Sample point ---- Residential area

\begin{tabular}{|c|c|c|c|c|c|c|c|}
\hline Label & Name & $\begin{array}{c}\text { Building Height in } \\
\text { Stories }\end{array}$ & $\begin{array}{l}\text { Average Building } \\
\text { Height in Metres }\end{array}$ & Building Density & Floor Area Ratio & $\begin{array}{l}\text { Year of Completed } \\
\text { Construction }\end{array}$ & Characteristics \\
\hline $\mathrm{i}$ & $\begin{array}{l}\text { Fo Zu Ling } \\
\text { Community }\end{array}$ & 6,12 & 22.1 & $21 \%$ & 1.57 & 2008 & $\begin{array}{l}\text { The buildings are evenly } \\
\text { distributed. The overall } \\
\text { greening is good. The parking } \\
\text { area is paved with permeable } \\
\text { grass bricks. The central green } \\
\text { space is equipped with } \\
\text { children's facilities, pavilions, } \\
\text { benches, etc. }\end{array}$ \\
\hline
\end{tabular}

Investigation sample point

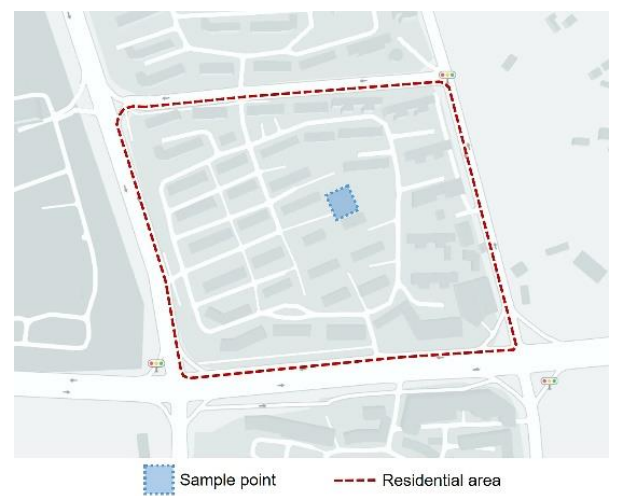




\section{References}

1. Zhang, J.; Yu, Z.; Cheng, Y.; Chen, C.; Wan, Y.; Zhao, B.; Vejre, H. Evaluating the disparities in urban green space provision in communities with diverse built environments: The case of a rapidly urbanizing Chinese city. Build. Environ. 2020, 183, 107170. [CrossRef]

2. Chen, X.; Xu, Y.; Yang, J.; Wu, Z.; Zhu, H. Remote sensing of urban thermal environments within local climate zones: A case study of two high-density subtropical Chinese cities. Urban Clim. 2020, 31, 100568. [CrossRef]

3. Xiong, Y.; Liu, J.; Kim, J. Understanding differences in thermal comfort between urban and rural residents in hot summer and cold winter climate. Build. Environ. 2019, 165, 106393. [CrossRef]

4. Wu, Z.; Chen, L. Optimizing the spatial arrangement of trees in residential neighborhoods for better cooling effects: Integrating modeling with in-situ measurements. Landsc. Urban Plan. 2017, 167, 463-472. [CrossRef]

5. Zhang, L.; Zhan, Q.; Lan, Y. Effects of the tree distribution and species on outdoor environment conditions in a hot summer and cold winter zone: A case study in Wuhan residential quarters. Build. Environ. 2018, 130, 27-39. [CrossRef]

6. Caniato, M.; Gasparella, A. Discriminating People's Attitude towards Building Physical Features in Sustainable and Conventional Buildings. Energies 2019, 12, 1429. [CrossRef]

7. Caniato, M.; Bettarello, F.; Ferluga, A.; Marsich, L.; Schmid, C.; Fausti, P. Thermal and acoustic performance expectations on timber buildings. Build. Acoust. 2017, 24, 219-237. [CrossRef]

8. Peng, Y.; Feng, T.; Timmermans, H. A path analysis of outdoor comfort in urban public spaces. Build. Environ. 2019, 148, 459-467. [CrossRef]

9. Golasi, I.; Salata, F.; Vollaro, E.D.L.; Coppi, M.; Vollaro, A.D.L. Thermal Perception in the Mediterranean Area: Comparing the Mediterranean Outdoor Comfort Index (MOCI) to Other Outdoor Thermal Comfort Indices. Energies 2016, 9, 550. [CrossRef]

10. Deevi, B.; Chundeli, F.A. Quantitative outdoor thermal comfort assessment of street: A case in a warm and humid climate of India. Urban Clim. 2020, 34, 100718. [CrossRef]

11. Li, Y.; Rezgui, Y.; Guerriero, A.; Zhang, X.; Han, M.; Kubicki, S.; Yan, D. Development of an adaptation table to enhance the accuracy of the predicted mean vote model. Build. Environ. 2020, 168, 106504. [CrossRef]

12. Du, H.; Yang, C. Re-visitation of the thermal environment evaluation index standard effective temperature (SET*) based on the two-node model. Sustain. Cities Soc. 2020, 53, 101899. [CrossRef]

13. Wang, C.; Zhan, W.; Liu, Z.; Li, J.; Li, L.; Fu, P.; Huang, F.; Lai, J.; Chen, J.; Hong, F.; et al. Satellite-based mapping of the Universal Thermal Climate Index over the Yangtze River Delta urban agglomeration. J. Clean. Prod. 2020, 277, 123830. [CrossRef]

14. Lai, P.-C.; Choi, C.C.; Wong, P.; Thach, T.Q.; Wong, M.S.; Cheng, W.; Krämer, A.; Wong, C.-M. Spatial analytical methods for deriving a historical map of physiological equivalent temperature of Hong Kong. Build. Environ. 2016, 99, 22-28. [CrossRef]

15. Feng, X.; He, C.; Fang, Z.; Ji, Z. Present Research on Outdoor Thermal Comfort. Build. Sci. 2017, 33, 152-158. [CrossRef]

16. Fang, Z.; Lin, Z.; Mak, C.M.; Niu, J.; Tse, K.-T. Investigation into sensitivities of factors in outdoor thermal comfort indices. Build. Environ. 2018, 128, 129-142. [CrossRef]

17. Salata, F.; Golasi, I.; Vollaro, R.D.L.; Vollaro, A.D.L. Outdoor thermal comfort in the Mediterranean area. A transversal study in Rome, Italy. Build. Environ. 2016, 96, 46-61. [CrossRef]

18. Nazarian, N.; Fan, J.; Sin, T.; Norford, L.; Kleissl, J. Predicting outdoor thermal comfort in urban environments: A 3D numerical model for standard effective temperature. Urban Clim. 2017, 20, 251-267. [CrossRef]

19. Taleghani, M.; Kleerekoper, L.; Tenpierik, M.; van den Dobbelsteen, A. Outdoor thermal comfort within five different urban forms in the Netherlands. Build. Environ. 2015, 83, 65-78. [CrossRef]

20. Du, H.; Cai, Y.; Zhou, F.; Jiang, H.; Jiang, W.; Xu, Y. Urban blue-green space planning based on thermal environment simulation: A case study of Shanghai, China. Ecol. Indic. 2019, 106, 105501. [CrossRef]

21. Zhao, Q.; Sailor, D.J.; Wentz, E.A. Impact of tree locations and arrangements on outdoor microclimates and human thermal comfort in an urban residential environment. Urban For. Urban Green. 2018, 32, 81-91. [CrossRef]

22. Xu, M.; Hong, B.; Mi, J.; Yan, S. Outdoor thermal comfort in an urban park during winter in cold regions of China. Sustain. Cities Soc. 2018, 43, 208-220. [CrossRef]

23. Xue, F.; Gou, Z.; Lau, S.S.Y. Green open space in high-dense Asian cities: Site configurations, microclimates and users' perceptions. Sustain. Cities Soc. 2017, 34, 114-125. [CrossRef]

24. Amindeldar, S.; Heidari, S.; Khalili, M. The effect of personal and microclimatic variables on outdoor thermal comfort: A field study in Tehran in cold season. Sustain. Cities Soc. 2017, 32, 153-159. [CrossRef]

25. Zhang, L.; Deng, Z.; Liang, L.; Zhang, Y.; Meng, Q.; Wang, J.; Santamouris, M. Thermal behavior of a vertical green facade and its impact on the indoor and outdoor thermal environment. Energy Build. 2019, 204, 109502. [CrossRef]

26. Niu, J.; Hong, B.; Geng, Y.; Mi, J.; He, J. Summertime physiological and thermal responses among activity levels in campus outdoor spaces in a humid subtropical city. Sci. Total. Environ. 2020, 728, 138757. [CrossRef]

27. Watanabe, S.; Nagano, K.; Ishii, J.; Horikoshi, T. Evaluation of outdoor thermal comfort in sunlight, building shade, and pergola shade during summer in a humid subtropical region. Build. Environ. 2014, 82, 556-565. [CrossRef]

28. Ministry of Housing and Urban-Rural Development of the People's Republic of China. Code for Thermal Design of Civil Building GB 50176-2016; China Architecture \& Building Press: Beijing, China, 2016. 
29. Ye, X.; Chen, F.; Hou, Z. The Effect of Temperature on Thermal Sensation: A Case Study in Wuhan City, China. Procedia Eng. 2015, 121, 2149-2156. [CrossRef]

30. Ministry of Housing and Urban-Rural Development of the People's Republic of China. Standard for Urban Residential Area Planning and Design GB 50180-2018; China Architecture \& Building Press: Beijing, China, 2018.

31. Hu, W. Planning Principle and Design Method of Residential Area; China Architecture \& Building Press: Beijing, China, 2007; pp. 35-41.

32. Djekic, J.; Djukic, A.; Vukmirovic, M.; Djekic, P.; Brankovic, M.D. Thermal comfort of pedestrian spaces and the influence of pavement materials on warming up during summer. Energy Build. 2018, 159, 474-485. [CrossRef]

33. Chen, L.; $\mathrm{Ng}$, E.Y.Y. Outdoor thermal comfort and outdoor activities: A review of research in the past decade. Cities 2012, 29, 118-125. [CrossRef]

34. Shooshtarian, S.; Lam, C.K.C.; Kenawy, I. Outdoor thermal comfort assessment: A review on thermal comfort research in Australia. Build. Environ. 2020, 177, 106917. [CrossRef]

35. ASHRAE. ANSI/ASHRAE Standard 55-2017. Thermal Environmental Conditions for Human Occupancy; ASHRAE: Atlanta, GA, USA, 2017.

36. Xi, T.; Li, Q.; Mochida, A.; Meng, Q. Study on the outdoor thermal environment and thermal comfort around campus clusters in subtropical urban areas. Build. Environ. 2012, 52, 162-170. [CrossRef]

37. Šebjan, U.; Tominc, P. Impact of support of teacher and compatibility with needs of study on usefulness of SPSS by students. Comput. Hum. Behav. 2015, 53, 354-365. [CrossRef]

38. Schober, P.; Boer, C.; Schwarte, L.A. Correlation Coefficients: Appropriate use and interpretation. Anesth. Analg. 2018, 126, 1763-1768. [CrossRef]

39. Gao, J. Comparative Analysis and Application of Statistical Methods for Librarians' Evaluation. Res. Libr. Sci. 2019, 9-14. [CrossRef]

40. Ji, L.; Xi, Z.; Chen, Z.; Liu, Y. Study on climatic characteristics and assessment methods of high tempera-ture weather in Jilin province. J. Meteorol. Environ. 2020, 36, 49-54. [CrossRef]

41. Feng, K. Spatial and temporal variation characteristics of cold weather days with different grades in China from 1961 to 2017. Resour. Environ. Yangtze Basin 2020, 29, 150-163. [CrossRef]

42. Huang, Z.; Gou, Z.; Cheng, B. An investigation of outdoor thermal environments with different ground surfaces in the hot summer-cold winter climate region. J. Build. Eng. 2020, 27, 100994. [CrossRef]

43. Mao, Y. Study on Climate Adaptability of Human Beings to Thermal Comfort in China. Ph.D. Thesis, Xi'an University of Architecture and Technology, Xi'an, China, 2006. [CrossRef]

44. Chen, F. Architecture and Climate-Wind Circumstance in Hot-Summer and Cold-Winter. Ph.D. Thesis, Tongji University, Shanghai, China, 2007. [CrossRef]

45. Abdollahzadeh, N.; Biloria, N. Outdoor thermal comfort: Analyzing the impact of urban configurations on the thermal performance of street canyons in the humid subtropical climate of Sydney. Front. Arch. Res. 2021, 10, 394-409. [CrossRef]

46. Krüger, E.; Minella, F.; Rasia, F. Impact of urban geometry on outdoor thermal comfort and air quality from field measurements in Curitiba, Brazil. Build. Environ. 2011, 46, 621-634. [CrossRef]

47. Kubota, T.; Miura, M.; Tominaga, Y.; Mochida, A. Wind tunnel tests on the relationship between building density and pedestrianlevel wind velocity: Development of guidelines for realizing acceptable wind environment in residential neighborhoods. Build. Environ. 2008, 43, 1699-1708. [CrossRef]

48. Huang, Z.; Cheng, B.; Gou, Z.; Zhang, F. Outdoor thermal comfort and adaptive behaviors in a university campus in China's hot summer-cold winter climate region. Build. Environ. 2019, 165, 106414. [CrossRef] 